STREAM GAGING BY CONTINUOUS INJECTION

OF TRACER ELEMENTS

by

William Lewis Werrell

A Thesis Submitted to the Faculty of the GRADUATE COMIMITTEE ON HYDROLOGY

In Partial Fulfillment of the Requirements For the Degree of MASTER OF SCIENCE

In the Graduate College

THE UNIVERSITY OF ARIZONA 


\section{STATEMENT BY AUTHOR}

This thesis has been submitted in partial fulfillment of requirements for an advanced degree at The University of Arizona and is deposited in the University Library to be made available to borrowers under rules of the library.

Brief quotations from this thesis are allowable without special permission, provided that accurate acknowledgment of source is made. Requests for permission for extended quotation from or reproduction of this manuscript in whole or in part may be granted by the head of the major department or the Dean of the Graduate College when in his judgment the proposed use of the material is in the interests of scholar ship. In all other instances, however, permission must be obtained from the author.

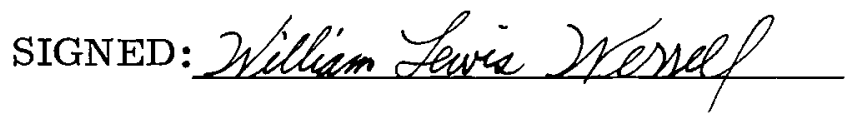

\section{APPROVAL BY THESIS DIRECTOR}

This thesis has been approved on the date shown below:

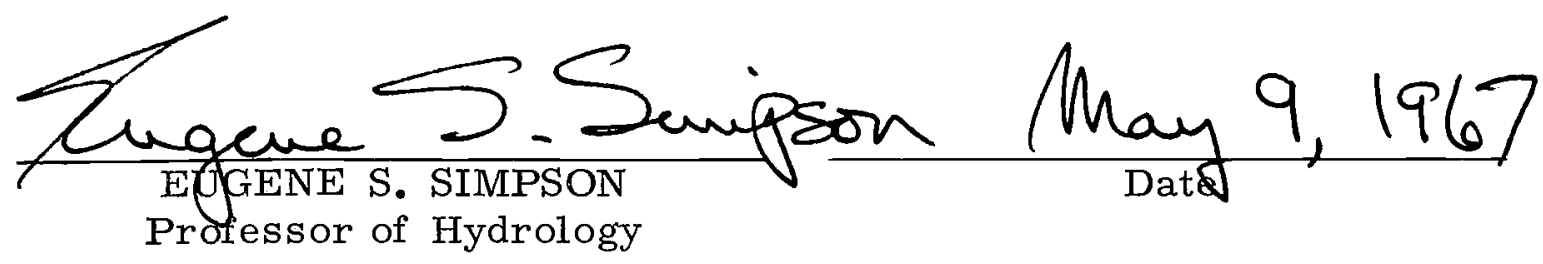




\section{ACKNOWLEDGMENTS}

The author wishes to thank Dr. E. S. Simpson, who suggested the thesis topic and directed the study. Acknowledgment also is given to Mr. Dallas Childers, who conducted the current-meter measurements on the discharge of Sabino Creek. Thanks are given to the following individuals, who accompanied me on field trips and served as sample collectors: my wife, Robin; Mr. and Mrs. Jack Edmonds; Mr. Stuart Brown; Mr. Robert Lichty; and Mr. Raymond Harshbarger. 
TABLE OF CONTENTS

Page

LIST OF ILLUSTRATIONS $\ldots \ldots \ldots \ldots \ldots \ldots$ vi

LIST OF TABLES $\ldots \ldots \ldots \ldots \ldots \ldots$ vii

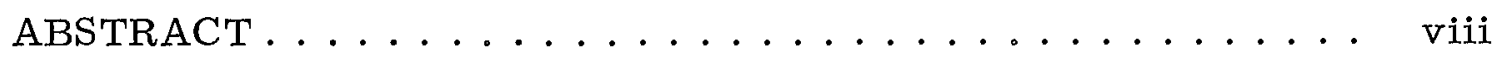

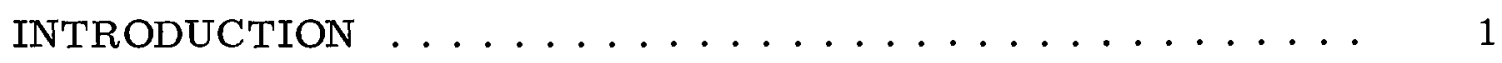

TRACER-DILUTION METHOD OF DETERMINING

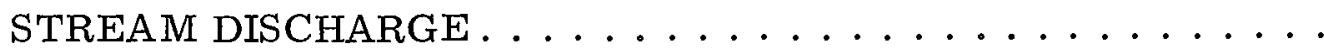

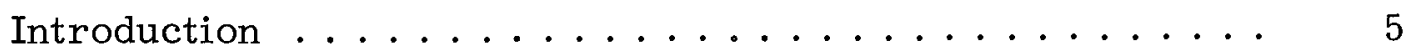

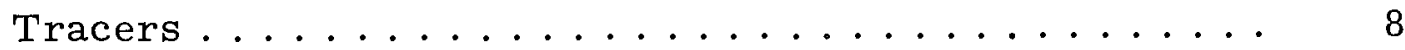

Fluorescein Dye-Dilution Method .............. 10

Dye Solutions . . . . . . . . . . . . . . 10

Background Fluorescence . . . . . . . . . . . 12

Computation of Stream Discharge . . . . . . . . 13

Dye Injection . . . . . . . . . . . . . . . 15

Mariotte-Flask Method . . . . . . . . . . 16

Floating-Syphon Method ................... 19

Constant-Head Tank Method. . . . . . . . . . 19

A Review of Mixing Length and Dispersion Equations . . 20

Dye Samples Collected . . . . . . . . . . . . . 23

Fluorometer Operating Procedure ........... 24

Laboratory Experiments . . . . . . . . . . . . . 30

Matching of Cuvettes ................. 30

Fluorescence Loss Due to Direct Sunlight . . . . . . . 32 
TABLE OF CONTENTS - Continued

Page

Field Experiments ..................... 38

Willow Creek Test . . . . . . . . . . . . . 39

Sabino Creek Test ................. 46

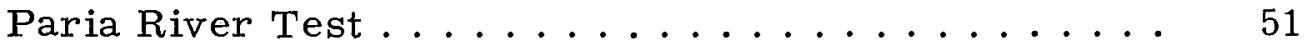

Chinle Wash Test.................. 55

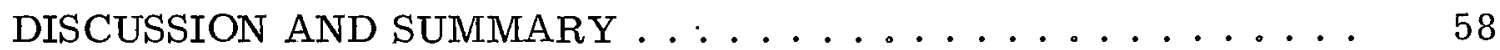

Possible Sources of Error. . . . . . . . . . . . 58

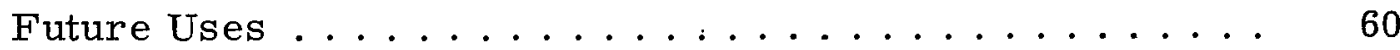

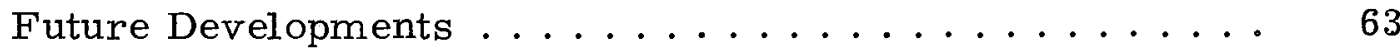

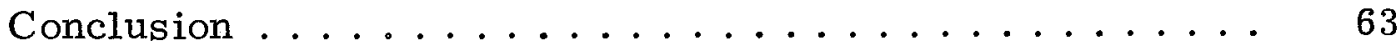

APPENDIX A-WILLOW CREEK TEST ........... 65

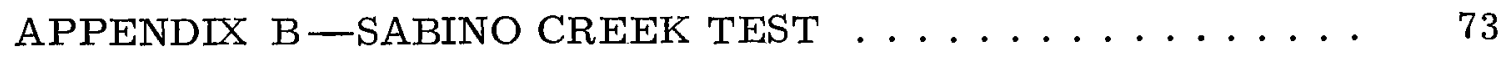

APPENDIX C-PARIA RIVER TEST . . . . . . . . 76

APPENDIX D-CHINLE WASH TEST $\ldots \ldots \ldots \ldots$

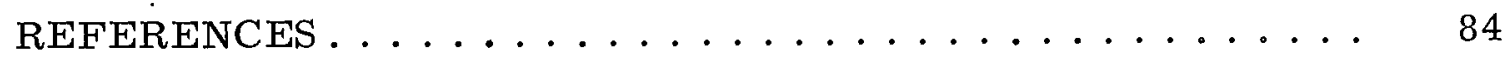




\section{LIST OF ILLUSTRATIONS}

Page

Figure

1. Mariotte flask, principle of operation.......... 17

2. Diagram of the Turner Model III

fluorometer optical system .............

3. Variation of fluorescence with exposure to sunlight . . . . . . . . . . .

4. Decay of Brilliant Pontacyl Pink B on exposure to direct sunlight $\ldots \ldots \ldots \ldots \ldots$

5. Flow in Willow Creek $\ldots \ldots \ldots \ldots \ldots$

6. Recorder chart from Willow Creek diversion of Black River gaging station ............

7. Recorder chart from Sabino Creek gaging station .....

8. Flow in Sabino Creek. ................

9. Dye injection at the upper end of the Paria

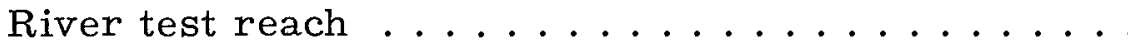

10. Recorder chart from Paria River gaging station......

11. Recorder chart from Chinle Wash gaging station ..... 


\section{LIST OF TABLES}

Table

1. Discharge computations for Sabino Creek based on U.S. Geological Survey gagingstation record and dye-dilution measurement . . . . . . 


\title{
STREAM GAGING BY CONTINUOUS INJECTION \\ OF TRACER ELEMENTS
}

By

William Lewis Werrell

\begin{abstract}
The practical application of the use of fluorescent-dye tracer elements as a means of determining stream discharge was the consideration of this study. Although this approach is not new in principle, recent developments in fluorometry and the development of new and less expensive fluorescent dyes warrant reappraisal of the method.

During this study, the proper use of the fluorometer was mastered, properties of the dye were examined by laboratory tests, and four field tests were conducted. Three of the field tests allowed direct comparison between discharge computed by the dye-dilution method and discharge measured by a current meter; the maximum variation between the results of these tests was 11 percent.
\end{abstract}


The dye-dilution method may be used on streams in the Southwest for high-water measurements of flow above wading stage where no cableway is present or where no adequate current-meter measurement section can be found. The possibility of future automation of this measurement system holds promise for the rating of new gaging stations and for providing streamflow records in remote areas. 


\section{INTRODUCTION}

The semiarid and desert regions of the United States present special problems in the determination of the factors included in a water budget-surface-water inflow, outflow, evapotranspiration, etc. In these regions, efficient utilization of the available water resources is of utmost importance in order to maintain even the present degree of water usage. In addition, the predicted rapid population growth will further tax the water resources.

The importance of surface water cannot be overestimated. Flowing streams offer the most accessible and often the most economic water supply for man's use. Streams maintain lakes and ponds for recreation and sustain the area's natural wildlife. Influent streams are the major source of ground-water recharge in areas of rapid ground-water decline. However, sediment problems are inherently connected with streamflow.

In the semiarid Southwest, streams that have small drainage areas flow intermittently, perhaps only two or three times a year in response to local rainfall; however, when precipitation does occur, a substantial part of the total runoff for the year may occur within a few 
hours. Steep stream gradients and the lack of vegetative cover allow rapid runoff. Rainstorms generate streamflow in which the rising limb of the hydrograph is characteristically steep, and the recession to zero flow may occur within minutes or hours.

As the need for accurate data for scientific water management becomes more critical, new methods for obtaining these data must be developed. The provision of these data, in a large part, is the responsibility of the U.S. Geological Survey. In order to obtain these data, surface-water gaging stations have been established throughout the Southwest. New stations constantly are being added to the existing program. In many places, these stations, by necessity, are established along sand-channel streambeds on alluvial plains. The establishment of the stage-discharge relations for these stations is difficult, time consuming, and never-ending. Discharge ratings for sand-channel streams are shifting continually, as the controlling section of the river changes. In many instances, it is difficult or impossible to measure the discharge by current-meter methods without a bridge or cableway, because the force of the current is too strong to permit wading. Some stations are not easily accessible, and often there is no flood warning because of their location in sparsely populated areas.

Present methods for the continuous determination of stream discharge are based on a stage-discharge relation, in which gage height, the independent variable, is determined by one of two types of 
gages - recording or nonrecording. Recording gages are necessary to record the stage-time relation, which is used with the stage-discharge relation to determine discharge. Stage recorders are either short- or long-term - 7-day or continuous - and are of the analog or digital type. Nonrecording gages used to measure stage are the staff, wire-weight, tape-weight, chain-weight, float, electric, hook, and pressure gages, which may be used alone or in conjunction with continuous recorders. The stage-discharge relation is determined by measuring the discharge, at different stages, with a current meter or through computations using indirect methods.

Factors that affect the stage-discharge relations for individual streams are scour and fill of the streambed, streambed regime, variable slope, ice, aquatic vegetation, debris on the control, and changes in velocity and direction of the current.

Indirect measurements used to determine the instantaneous peak discharge are the slope area (application of the Bernoulli energy equation) and flow through contracted openings, culverts, over roadway embankments, and over dams. The crest-stage gage, which measures only the peak stage of a particular flow, is often used to assist with indirect measurements.

The extremely short periods of flow, the scour-on-rise and fill-on-recession characteristics of sand-channel streams, the difficulty of making current-meter measurements, and the inaccessibility 
of stations that have no flood-warning system present serious difficulties in collecting surface-water data in the Southwest and other arid or semiarid regions. Stream gaging by continuous injection and monitoring of tracer elements shows promise in overcoming many of these difficulties. 


\section{TRACER-DILUTION METHOD OF DETERMINING STREAM DISCHARGE}

\section{Introduction}

The tracer-dilution method of determining stream discharge consists of injecting a highly concentrated but small quantity of tracer solution of known or determinable strength into streamflow. After release, the fluid is allowed to flow downstream for a distance, so that it will become homogeneously, vertically, and laterally dispersed throughout the stream cross section. Monitoring of the tracer is conducted downstream from this point. By determining the amount of tracer dilution, the quantity of flow can be computed, if it can be assumed that no loss or gain of the tracer occurred during the test.

Discharge computed by the dye-dilution method is the quantity of flow occurring at the point where homogeneous mixing of the dye takes place. Assuming that there is no loss or gain of dye during the test and that the stream is not influent, valid sampling may be conducted at any point downstream. Thus, for the rating of a gaging station, the dye-dilution test must be located so that mixing will occur upstream from the gaging station; sampling should be conducted at the 
station if possible. If additional water is added to the stream, such as tributary inflow, sampling must be done at some distance downstream, the distance being sufficient so that the dye will become homogeneously mixed with the total or combined flow.

The cross-sectional area of the channel and the stream velocities are not necessary to determine discharge by the dye-dilution method, which is a great advantage. This eliminates the necessity of wading the stream or, during high flow, the need for a cable car. The dye-dilution method can be used in most reaches of the stream channel without regard for the usual factors that must be considered in proper selection of a current-meter measurement section or the factors that affect the choice of sections for a slope-area measurement-channel roughness, velocity direction, and straightness of channel.

At typical sand-channel gaging stations, the computation of the stage-time records requires the use of adjustment or shift curves due to scour-fill conditions in the channel. Between current-meter measurements, the proper adjustment of the stage record may be high1y speculative. The dye-injection method of computing flow eliminates this problem. Future development of a continuous sampling apparatus will allow complete automation of the dye-dilution method of determining stream discharge. Discharge measurements could be obtained at distant infrequently visited stations. This method will provide a rating 
for the stream at all stages at which flow occurs during a test. The rating will be subject to the percent deviation caused by channel shift; however, for the rating of many stations (crest-stage gage sites) this deviation will be within desired accuracy. Therefore, one continuous dye-injection test could suffice for a number of current-meter measurements. This 1 -flood rating technique may be especially important where different hydrologic studies are being conducted and station ratings are needed quickly rather than waiting until gaging personnel have been fortunate enough to observe and gage flow at a wide range of stream stages.

The disadvantages of the dye-dilution method are: (1) high cost of the fluorometer; (2) the delicacy of the instrument, which tends to limit field usage; (3) the necessity for an electrical power source for operation; (4) the complexity of fluorometer service; (5) the need for exact measurement of weights and volumes in the laboratory; and (6) the cost of the fluorescent dyes.

At the present time the cost of the dyes is $\$ 16.00$ per pound; the dye may be purchased in powder or solution form. A powderform dye was used in this study-Brilliant Pontacyl Pink B.

Without modification, the fluorometer is capable of detecting fluorescence of more than $2 \mathrm{ppb}$ (parts per billion); fluorometer modification will allow detection at considerably lower concentration. The 
amount of dye used is a function of the lower limit of detectability of the fluorometer, the peak amount of water into which the dye is injected, and the length of time of injection. Extreme cleanliness is necessary in conducting calibration and apparatus preparation, which requires a special physical facility and considerable time for mixing and washing before and after each test. Mixing of the injection solution may be extremely messy, causing stains on equipment and clothing. This is especially true if the dye is powdered. The fine powder is introduced easily into the air, and within a few hours, although no dye is visible on objects in a room, the wetting of any surface will produce a highly concentrated dye solution. Obviously, it is necessary that dye mixing be done elsewhere than in the cleaning and (or) fluorometer room.

\section{Tracers}

Originally, it was proposed that two tracers be examined in this study - salt and a fluorescent dye. The use of salt as a tracer was soon deemed impractical. The proposal called for monitoring the salt concentration by electrical conductivity of the stream water. However, to increase the electrical conductivity by a measurable amount would add large quantities of salt to the stream. Because of the large amount of salt necessary, the physical space and weight required for salt 
injection is probably impractical; also, downstream water users might complain about the change in the chemical quality of the water. Salt, however, could be used for stream gaging if chemical analyses for chlorine rather than conductivity measurement were made or if a flame photometer was used. Barsby and Cole (1963) detected salt using a flame photometer, which indicated cations at levels as low as $1 \mathrm{ppm}$ (part per million). The time and expense that would have been involved in using either of the above processes would have been beyond the scope of the writer's resources.

Another tracer that has been used to determine discharge is the radioactive isotope (U.S. Bureau of Reclamation and others, 1961). Common isotopes used are cesium-134, sodium-24, bromine-82, and gold-198. The advantages of the use of isotopes for tracers are the very low concentrations necessary for detection and the low radioactive background of the stream. Reasonably accurate in situ field detection by use of portable instrumentation also is possible. Disadvantages arising from the peculiar nature of the toxicity are: (1) the tracer must be kept in a lead container from its point of origin until it is put in the stream; (2) personnel must be monitored for radioactive exposure during the test; (3) it must be demonstrated to the appropriate licensing agencies that the study will be harmless to the surrounding population. In addition, it has been found that people are hostile to the 
use of radioactive isotopes under any condition. Some of the purely technical disadvantages are the high cost of the instrumentation and tracer and the low half life of some tracers, which puts a constraint on available time, or the high half life of other tracers, which puts a constraint on maximum concentration.

Therefore, only the fluorescent dye was tested as a tracer in determining stream discharge. In low concentrations the dye is visually undetectable, but it can be detected in extremely low concentrations using a fluorometer. Many fluorescent dyes do not alter the odor or taste of the water. They are not harmful to plants or animals, and the dye used in this study is manufactured for the textile industry and has been used in women's cosmetics.

$\underline{\text { Fluorescein Dye-Dilution Method }}$

\section{Dye Solutions}

The dye used in all the experiments - Brilliant Pontacyl Pink $\mathrm{B}$ - is in powder form. The dye was selected because of its reported low adsorption characteristics, large range in $\mathrm{pH}$ tolerance, and lack of salinity effect (Feuerstein and Selleck, 1963; Wright and Collings, 1964).

Two types of dye solution are required. First, a quantity of dye must be prepared for use in the calibration of the fluorometer. 
This solution may be very small in volume but must be prepared to exacting standards. The preparation of standard solutions is accomplished most accurately by the use of clean dry laboratory equipment. A standard solution is obtained by diluting a high-concentration solution with distilled water; large-volume pipettes and volumetric flasks are used in this procedure. Fluorometer calibration requires two or more standard solutions, all of which are within the range of detectable concentrations by the fluorometer. Each concentration is checked on all fluorometer ranges, and the corresponding dial readings are recorded. The second type of dye solution is for injection into the streamflow. A relatively large volume of dye solution is required, but it is not necessary for the dye concentration to be specifically known at the time of preparation. However, ample dye must be injected into the stream to be within the detectable limits of the fluorometer after stream dilution. Once prepared, the exact dye concentration may be determined by the fluorometer using the above-mentioned calibration standards.

A volume of $1 \mathrm{ml}$ of water at $60^{\circ} \mathrm{F}$ is equal to $1 \mathrm{cc}$, and $1 \mathrm{cc}$ of water at $60^{\circ} \mathrm{F}$ is equal to $1 \mathrm{~g}$. Therefore, $1 \mathrm{~g}$ of dye in solution with $1,000 \mathrm{ml}$ of water provides a dye concentration of 1 million ppb (parts per billion), or $0.25 \mathrm{~g}$ provides a solution of $250,000 \mathrm{ppb}$ in $1,000 \mathrm{ml}$. No adjustment was made for water temperatures. To compute the approximate concentration of injection solution, the value for $\mathrm{C}_{1}$ is 
obtained in equation (4) after estimating or guessing a reasonable value for peak discharge. To assure complete homogeneity of the dye-injection solution, dye may be predissolved in small amounts of liquid before being mixed in the large injection apparatus.

\section{Background Fluorescence}

The natural fluorescence of river or stream water is termed "background." It is generally very low, ranging from 0 to 1 or 2 units on range 30 of the fluorometer. This value must be determined and subtracted from all readings obtained from the samples collected during a dye-dilution test. Samples of water collected upstream of the injection point or prior to the dye-cloud arrival at the sampling station are used to establish the magnitude of the fluorescence of the background. It is suggested that a sample be collected at the end of the test to determine if any variation in background fluorescence occurred during the test. No variation in background was experienced in the tests conducted in conjunction with this thesis. Adjustment for background may be accomplished (1) by adjustment of the fluorometer dial so that readings will be indicative of the injected fluorescence only, (2) by arithmetically subtracting the background value from the fluorometer dial reading obtained for each sample, or (3) by adjustment of the $y$ axis of a dial-time plot of the data points. 


\section{Computation of Stream Discharge}

The dye-dilution technique used in this study involved continuous injection, at a constant rate, of a homogeneous dye solution. If

$$
\begin{aligned}
\mathrm{C}_{\mathrm{O}}= & \text { Natural fluorescence background of the stream water; } \\
\mathrm{C}_{1}= & \text { Concentration of injection fluid; } \\
\mathrm{C}_{2}= & \text { Concentration of stream water after the injection } \\
& \text { fluid is homogeneously mixed; } \\
\mathrm{Q}= & \text { Stream discharge, in cfs; and } \\
\mathrm{q}= & \text { Injection rate, in } \mathrm{ml} \text { per sec }
\end{aligned}
$$

or

$$
q\left(3.53 \times 10^{-5}\right)=\text { Injection rate, in cfs, }
$$

then

the amount of tracer added to the stream per unit time may be expressed as:

$$
C_{1}\left[q\left(3.53 \times 10^{-5}\right)\right]
$$

and

the amount of tracer in the stream, after mixing, is:

$$
C_{2}\left[q\left(3.53 \times 10^{-5}\right)+Q\right]-C_{O} Q
$$


or

$$
\mathrm{C}_{2}\left[\mathrm{q}\left(3.53 \times 10^{-5}\right)\right]+\mathrm{C}_{2} \mathrm{Q}-\mathrm{C}_{\mathrm{O}} \mathrm{Q}
$$

Because the theory of the dye-dilution method assumes no loss or gain of the tracer material, we may equate equations (1) and (2), thus:

$$
C_{1}\left[q\left(3.53 \times 10^{-5}\right)\right]=C_{2}\left[q\left(3.53 \times 10^{-5}\right)\right]+C_{2} Q-C_{O} Q
$$

or

$$
q\left(3.53 \times 10^{-5}\right)\left(C_{1}-C_{2}\right)=Q\left(C_{2}-C_{O}\right)
$$

or

$$
\frac{Q}{q\left(3.53 \times 10^{-5}\right)}=\frac{C_{1}-C_{2}}{C_{2}-C_{O}}
$$

or

$$
Q=q\left(3.53 \times 10^{-5}\right)\left[\frac{C_{1}-C_{2}}{C_{2}-C_{O}}\right]
$$

or

$$
Q=q\left(3.53 \times 10^{-5}\right)\left[\frac{C_{1}}{C_{2}-C_{o}}-\frac{C_{2}}{C_{2}-C_{O}}\right]
$$

If we consider that the background has been compensated for, our equation becomes:

$$
Q=q\left(3.53 \times 10^{-5}\right)\left[\frac{C_{1}}{C_{2}}-\frac{C_{2}}{C_{2}}\right]
$$


or

$$
Q=q\left(3.53 \times 10^{-5}\right)\left[\frac{C_{1}}{C_{2}}-1\right] \text {. }
$$

Because the concentration of the stream water is extremely small compared to the concentration of the injection solution, we may simplify equation (3) to:

$$
Q=\frac{C_{1}}{C_{2}} q\left(3.53 \times 10^{-5}\right) .
$$

It is interesting to note that the concentrations are expressed as a ratio. Thus, the units may be either parts per billion or fluorometer dial readings if all readings are taken on the same range and the fluorometer is operating properly in a linear manner.

\section{Dye Injection}

The rate that dye is injected into the stream must be known. Dye is injected at a constant rate to facilitate calculations of stream discharge using the dye-dilution method. All types of constant-rate discharge apparatus - Mariotte flask, floating syphon, and constanthead tank-are designed so that the fluid-head of the system remains constant as the fluid is discharged. 
Mariotte-flask method. --The constant-rate injection system used in this study is termed the "Mariotte-flask method" (fig. 1). The Mariotte flask apparatus is simply designed, constructed, and compact and does not require a power source. The flask is filled with a highly concentrated dye solution and is sealed airtight, except for the air tube. Fluid is discharged from the flask by opening the orifice at the bottom. As fluid escapes, an area of reduced pressure is created at the top of the flask, and, as a result, the liquid level within the air tube begins to fall. Continued discharge further reduces the pressure in the upper part of the flask, and the liquid level in the air tube continues to fall until, finally, air bubbles are released from the bottom of the tube. At this time, atmospheric pressure exists at the bottom of the tube, regardless of the fluid level, and the flask begins to discharge at a uniform rate and continues to do so until the liquid level falls below the bottom of the air tube.

It is suggested that the flask be made of rust-resistant material to reduce the possibility of rust or scale plugging the orifice. The flask should be thoroughly flushed and the orifice cleansed after use. A cockstop-type valve should be used. During transport of a loaded flask to a higher altitude, the air tube should be plugged at the top or removed from the flask, in order to prevent reduced atmospheric pressure from forcing the injection fluid out of the air tube and spilling out. 


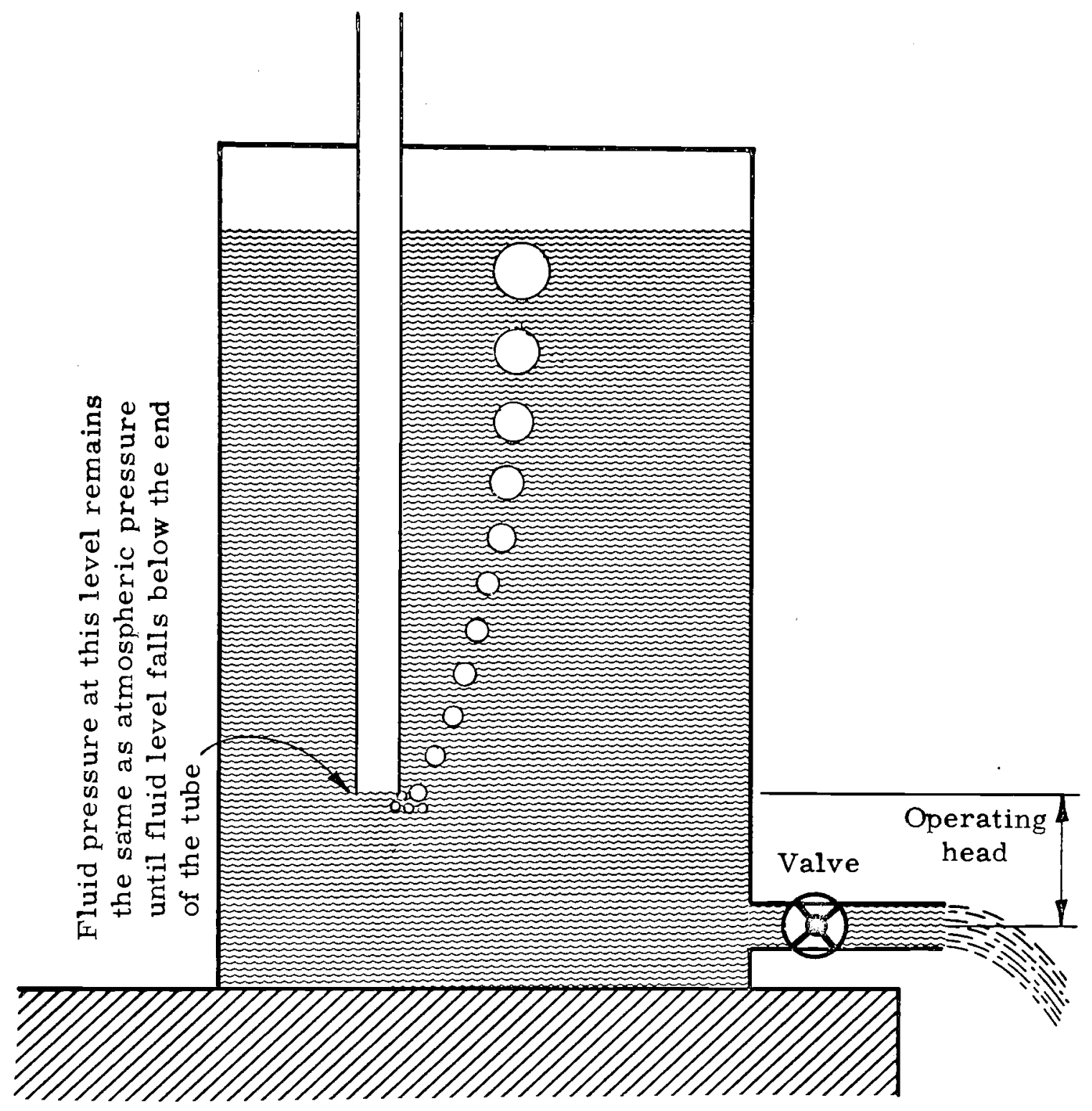

Figure 1. --Mariotte flask, principle of operation. 
Mr. F. A. Kilpatrick of the U.S. Geological Survey, who has been experimenting with the method at Denver, Colorado, stated (oral communication), that difficulties are encountered in the operation of a Mariotte flask designed to deliver at a rate of less than $1 \mathrm{ml}$ per sec. The reduced pressure in the valve allows the release of air from the water. These air bubbles slowly build up, and cause a decrease in orifice area and a decrease in discharge rate. He found that de-aired water and (or) the addition of a few drops of liquid laboratory detergent will alleviate the problem.

In order to determine accurately the rate of flow from the Mariotte flask and to substantiate the fact that the discharge was constant, three experiments were conducted during this study. First, a card was made in the first few minutes of discharge to check the trajectory angle. The card was cut so that when it was placed along the upper part of the discharge tube a corner barely touched the discharge stream. The card was placed in the same positions at different intervals during the discharge period. Toward the end of the test, the corner of the card still barely intersected the discharge stream. The second and third experiments were conducted at the same time as the first. In the second experiment a part of the discharge was caught in a graduated cylinder during a timed interval. In the third experiment the amount of discharge collected during this interval was weighed. 
The variation, as determined by a graduated cylinder, was less than 1 percent: 7.99 to $8.04 \mathrm{ml}$ per sec. The variation, as determined by weight, also was less than 1 percent: 7.98 to $8.03 \mathrm{ml}$ per sec.

Floating-syphon method。--The floating-syphon method has about the same advantages as the Mariotte-flask method. The floating syphon consists of an open container filled with fluid for discharge, a freely floating platform on the fluid surface, and the syphon tube, which is attached to the platform and projects to the lower surface of the platform. The tube is an inverted " $U$," the height of which must exceed the depth of the container. The discharge end of the syphon tube must extend beyond the edge of the container. The hydraulic head is adjusted by the length to which the discharge end of the tube extends below the elevation of the intake opening of the tube. Once the syphon is started, discharge is constant; as the fluid level falls, the floating platform is lowered, but the relative positions of the tube openings are constant.

Constant-head tank method, -- Recent industrial needs for a constant low-rate discharge apparatus have prompted the development of a new product - the constant-head tank. The high cost of the apparatus is the main disadvantage. The tank, marketed under the name of Aerofeed, is a closed container with a pressure cap of air. A highly sensitive pressure valve adjusts the orifice aperture so that the flow 
rate is constant as the pressure head of air is depleted. The low stable-flow rate for the apparatus is about $1 \mathrm{ml}$ per sec.

A Review of Mixing Length and Dispersion Equations

The exact distance required for homogeneous mixing of the dye with the unknown quantity of streamflow is a function of the different hydraulic properties of the stream downstream from the injection point-e.g., the roughness of the stream channel (Manning's n), hydraulic radius, etc. The point or number of points of injection also influence this distance. Generally, if dye injection is made at the stream's center, less distance will be necessary for homogeneous mixing than if injection was made at the stream's edge. In addition, if injection is made at several points across the stream, the distance required for homogeneous mixing will be farther reduced. The following equation used to determine the distance required for mixing was developed by Nobuhiro Yotsukura (engineer, U.S. Geological Survey, written communication, 1965):

$$
L=\frac{1.49}{2 \alpha^{2} \beta} \cdot \frac{\mathrm{R}^{1 / 6}}{\mathrm{n} \sqrt{\mathrm{g}}} \cdot \frac{\mathrm{W}^{2}}{\mathrm{D}_{\mathrm{m}}}
$$

where

$L=$ the distance downstream from the dye-solution injection point; 
$a=a$ constant that is given as 6 , for $L$ equal to the point where the dye first comes in contact with the banks and as 2 for $\mathrm{L}$ equal to the point of complete mixing of the dye;

$\beta=$ an empirically determined coefficient for which values have been found ranging from 0.3 to 0.8 in natural streams but which may have values over a greater range;

$R=$ the hydraulic radius of the channel;

$\mathrm{n} \quad=$ the Manning roughness coefficient;

$\mathrm{g}=$ gravitational acceleration;

$\mathrm{W}=$ the mean width of the stream; and

$D_{m}=$ the mean depth of the stream.

The following equations are listed by Andre (1964, p. 28) for determining the distance necessary for dye to become homogeneously mixed with streamflow.

D. E. Hull's equation:

$$
L=a Q^{1 / 3}
$$

where

$\mathrm{L}=$ minimum length required for homogeneous mixing; 
$\mathrm{a}=50$ if injection is performed at stream center, 200 if performed at stream edge; and

$\mathrm{Q}=$ discharge.

Rimmer's equation:

$$
L=0.13 k \frac{b^{2}}{d}
$$

where

$L_{L} \quad=$ length required for homogeneous mixing;

$\mathrm{b}=$ average width of the stream between injection point and sampling point;

$\mathrm{d}=$ average depth; and

$\mathrm{k}=\frac{\mathrm{C}(0.7 \mathrm{C}+6)}{\mathrm{g}}$

where

$\mathrm{C}=$ Chézy coefficient of the given reach with $15<$ $C<50$; and

$g=$ acceleration of gravity.

Perez's equation:

$$
\mathrm{L}=9.5 \mathrm{nd}
$$

where 
$\mathrm{L} \quad=$ length required for homogeneous mixing; and $\mathrm{n}=0.32 \mathrm{KR}^{1 / 6}$

where

$$
\mathrm{K}=\underset{\text { and }}{\text { coefficient }}=\frac{1.486}{\mathrm{n}} \text { of Manningt's equation; }
$$

$\mathrm{R}=$ hydraulic radius

$\mathrm{d}=$ average stream depth.

In this study the sampling point was always at a distance of more than 50 channel widths, this distance being about 10 times the computed value from any of the above equations.

\section{Dye Samples Collected}

Water samples were taken downstream from the point of homogeneous vertical and lateral mixing of the dye-injection solution. A small quantity of streamflow was collected in clear pharmaceutical dispensary vials of 5-dram capacity, which provided enough liquid to allow two separate tests on the fluorometer. The samples then were placed in a closed box to deter any fluorescence loss from the dye due to exposure to sunlight. Each sample taken on the plateau of the dye cloud allows computation of the instantaneous stream discharge. 


\section{Fluorometer Operating Procedure}

The G. K. Turner Model III fluorometer was used in this study. This electronic instrument operates on the principle of an optical bridge, which is analogous to the familiar Wheatstone bridge used in measuring electrical resistance. The optical bridge compares the difference in light intensity emitted from the sample and light intensity from a calibrated rear path (fig. 2). Comparison of the light intensities is made by a single photomultiplier, which alternately receives light from each path. The rotating light interrupter allows only light from one path to intercept the photomultiplier at any one time. A single mercury light source is used for each path of light. For the most part, the reliability of the instrument is due to the single light source and single photomultiplier, because any aging of the bulb, etc., will not affect the reading - all light beams are affected to the same extent. Differences in light intensity from the two paths cause the photomultiplier to rotate electrically the light cam and diffuse screen. The rotation of the light cam continues until the light intensity of both paths is equal, at which time the movement of the cam virtually ceases. The fluorescence dial is read at this time. The range selector is an operator-adjusted curtain that has four openings of different sizes. Light from the source is allowed to pass through one of the openings as it is radiated toward the sample. Samples containing high 


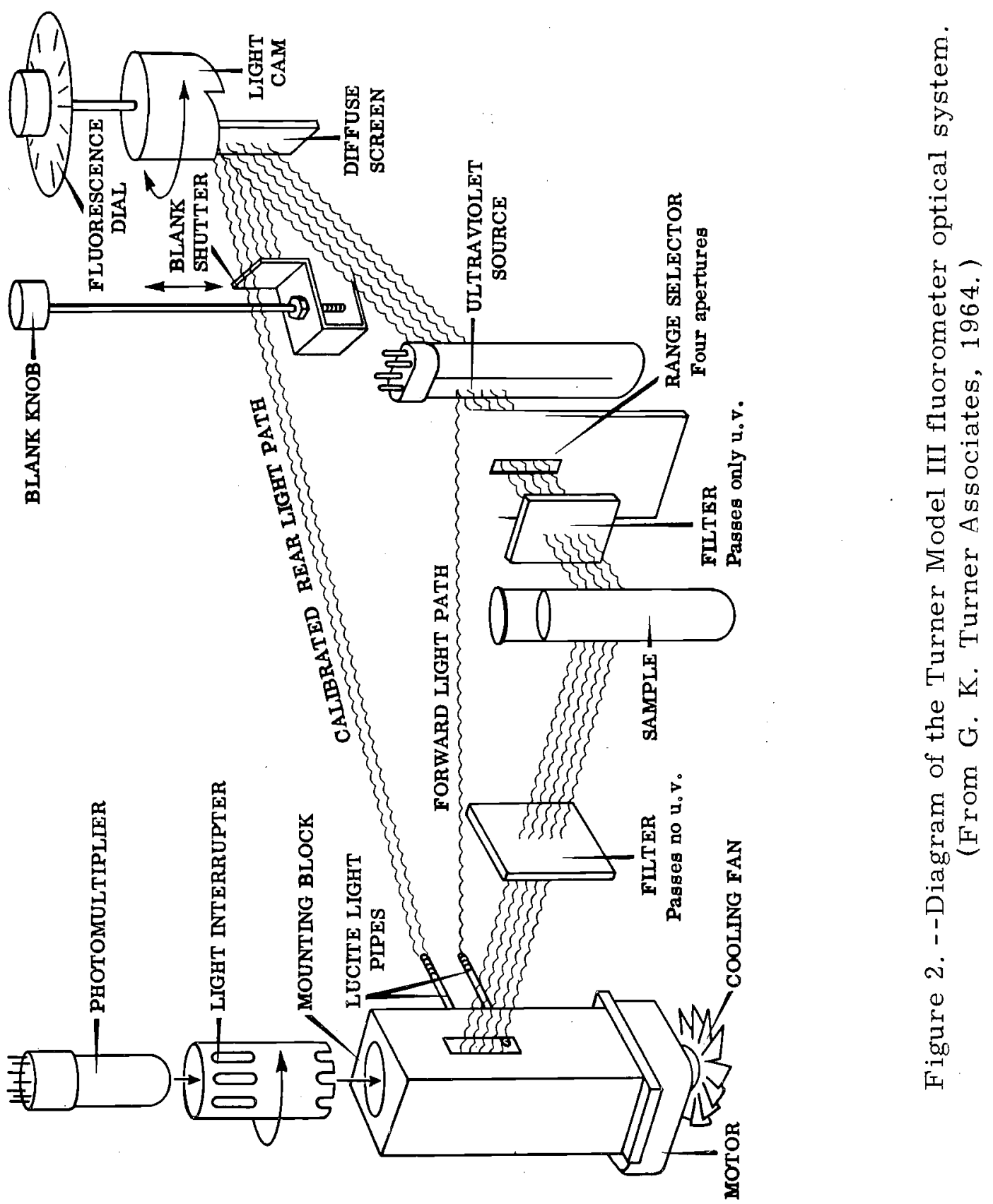


concentrations of fluorescein dye require the use of the smaller opening so that the fluorescence dial will not run off scale on the upper magnitude.

The fluorometer has two locations for optical filters. Both of these are on the forward light path, the first just before the sample and the second immediately after the sample. The filters allow light of only a very restrictive wavelength to pass. The first set of filters passes light that closely coincides to the peak absorption wavelength of the sample compound, and the second set passes light of the wavelength that the sample emits when excited by the light that passes the first filter. The two filter locations are at right angles to each other, so that if filter transmission is somewhat overlapping, only fluorescent light will reach the photomultiplier. The instrument was used without a special high-sensitivity green bulb or a high-sensitivity door, which increase the fluorometer sensitivity by 10-20 fold.

Although the instructions distributed with the fluorometer state that a warmup period of 15 minutes is sufficient for operation, repeated unsuccessful attempts to reproduce dial readings and (or) calibrate the fluorometer showed that a warmup period of several hours was necessary. A minimum warmup period of 6 hours was used for this study. 
Room temperature was thermostatically controlled at all times. Before examination of the sample, the vials were placed in the fluorometer room for a period of not less than 8 hours, which allowed for temperature stabilization. The sample was transferred from the vial to a temperature-stabilized cuvette. The cuvette was placed 2 or 3 feet from the fluorometer to prevent it from gaining heat from the fluorometer.

About the same length of time was taken to run each sample. Cuvettes were alternated as quickly as possible without carelessness. The fluorometer door was opened only when necessary in order to maintain a constant temperature within the chamber.

The main consideration when reading the fluorometer dial should be consistency of method. Whatever method is adopted by the operator for reading unknown samples must be adhered to when the fluorometer is calibrated. After the instrument is warm, it must be checked and possibly adjusted to assure that a reading of zero is shown when a blank or dummy cuvette is tested. The dial wavers slightly during operation, which is due to the servomotor movement, as it constantly seeks to establish the balance of the optical bridge system of the fluorometer. The dial movement is in the magnitude of \pm 0.25 unit and occurs every half second to a second. A gradual decrease in magnitude of fluorescence occurs owing to the gradual increase in 
temperature of the sample. The temperature of the chamber where the cuvette is placed is higher than the room temperature. The temperature of the chamber is higher because it is located close to the electronic circuitry of the fluorometer. The temperature of the sample also increases because the sample is subjected to intense light. The temperature increase causes a decrease in the fluorescence of the sample with time. The temperature increase occurs in 15 to $25 \mathrm{sec}-$ onds, and the fluorometer readings may drop 1 to 2 units during this time.

A complicated chemical breakdown of the dye occurs when it is subjected to ultraviolet light-either sunlight or the light from the fluorometer. However, this process is accelerated greatly when the dye is in the fluorometer, due to the intensity of the light. Laboratory experience has shown that if samples are allowed to remain in the fluorometer for less than 1 minute and allowed 30-60 minutes for restabilization to room temperature, the first reading usually could be repeated. Third attempts, however, usually resulted in lower readings. After considering the above physical variations and operating characteristics of the instrument, the procedure for testing a sample with the fluorometer is:

(1) A cuvette eontaining only distilled water (a blank sample) is placed in the fluorometer and the dial is set at zero. 
(2) A dye sample is placed in the fluorometer.

(3) The dial is read 20 seconds after the fluorometer door is closed. The time interval is sufficient to allow full dial movement from zero to any reading. This technique subjects all samples to the higher temperature of the instrument for the same length of time; therefore, the temperature of all samples is the same at the time of dial reading.

(4) The blank cuvette is placed in the fluorometer after the dial reading for the sample, which returns the fluorometer dial to the proximity of zero. Recent information from a $G . K$. Turner representative indicates that this step can be eliminated in future tests.

A cuvette is the small test tube that contains the solution to be tested in the fluorometer. To insure accurate fluorescent testing of the dye solution by the fluorometer, each cuvette was thoroughly cleansed and dried before it was filled with the solution to be tested. Elaborate washing of the cuvettes between tests is unnecessary, and thorough flushing with distilled water is adequate. After washing the cuvettes were placed in the cuvette stand in an inverted position to facilitate draining; the cuvettes were then transferred to the fluorometer laboratory where they were stored in a closed cupboard to retard 
collection of dust. A period of not less than 8 hours was allowed to elapse before the cuvettes were used, which allowed adequate time for drying and temperature stabilization. Cuvettes were handled only at their extremities to prevent the possible fluorescence of fingerprints from yielding an erroneous reading. The center of the cuvette is where the ultraviolet light from the fluorometer penetrates to determine the fluorescence of the solution being tested.

\section{Laboratory Experiments}

\section{Matching of Cuvettes}

The instructions for the operation of the fluorometer state that the instrument is designed in such a way that any variance in the optical properties of the cuvettes will not be shown in the readings. In order to substantiate this, two tests were made. In this study, 46 new cuvettes were used. Each cuvette was marked with an identifying number directly below the cuvette lip, well above the part of the cuvette through which light passes.

In the first test, a weak dye solution was mixed at an arbitrary strength. The solution was stirred with a magneticsstirrer for 15 minutes to assure homogeneity of the solution and was placed in a cupboard in the laboratory for 12 hours to allow temperature stabilization. After a 12-hour warmup period of the fluorometer, the 
cuvettes were filled with the dye solution and tested. A listing of the fluorometer readings that corresponded to the appropriate cuvette was made. All readings were obtained on range 30 . Of the 46 cuvettes tested, 42 produced readings of 22.5 units, and the remaining 4 produced readings of 23.0 units 。

The second test utilized a strong dye solution, and the same procedure was used as in test one. The readings in test two were obtained on range 1 , and the results are tabulated below:

\section{Number of cuvettes}

2

2

8

5

6

16

5

2
Fluorometer reading (units)

96.0

96.5

97.0

97.5

98.0

98.5

99.0

99.5

The four cuvettes that produced the higher readings in the first test gave readings of $97.0,97.5,98.0$, and 98.5 in the second test. The higher readings obtained in the first test are attributed to an inherent play of \pm 0.25 unit in the fluorometer dial. The greater variation in readings in the second test, however, is not completely understood, but it may be due to the increasing interference of one dye particle with another as concentration increased. 
The results of the two tests show that no calibration of individual cuvettes is necessary. The tests indicate that the errors for individual cuvettes are not systematic and that calibration of cuvettes would make no significant improvement on precision of final results.

\section{Fluorescence Loss Due to Direct Sunlight}

Adsorption of dye by apparatus and photochemical changes in dye on exposure to direct sunlight have been reported by many workers. Each of these factors causes a loss of dye from the system and results in error of the dye-dilution method, because the theory of the method assumes no loss or gain of dye during the procedure. The error would result in overcalculation of the true rate of streamflow. The most recent developments in fluorescent dyes are "Brilliant Pontacyl Pink B" and "Rhodamine WT Extra," which are manufactured by the General Analine and Film Corp. The manufacturer reports that the dyes have qualities superior to those of previous products -i. e., less adsorption on solids and greater photochemical stability. These properties were examined in two experiments using Brilliant Pontacyl Pink B.

The purpose of the first experiment was (1) to determine if dye adsorption would occur in measureable amounts on the plastic 
pharmaceutical dispensary vials used for dye sampling purposes, and (2) to examine the extent of photochemical change.

The dye solution was freshly prepared and magnetically stirred for 15 minutes in a glass beaker to assure homogeneity. Dye concentration was arbitrarily chosen but was within the detectable range of the fluorometer. Each of the 12 new vials was flushed with distilled water, dried, and filled with solution. Four of the vials were placed in a cupboard, and the 8 remaining vials were placed outdoors on the night of June 9, 1965. The 8 vials were exposed to the sun for different periods of time ranging from 1 to $4-1 / 2$ days (fig. 3 ). The vials that were exposed for less than 4-1/2 days were placed in the cupboard until the end of the test. Fluorometric testing of the solution was conducted in two periods - after the first day, 2 of the 4 vials in the cupboard were analyzed, and at the end of the 4-1/2 days, the remaining vials were analyzed. The conclusions from the first experiment are: (1) within the range of the experiment, the decay of fluorescence of the dye on exposure to direct sunlight is a linear function of time, (2) the decay of the dye that remained inside the cupboard was negligible, and (3) the amount of dye adsorption onto the plastic vials was negligible.

In 1967-January 9-14 and January 16-20-a second experiment was conducted to examine the photochemical decay properties of 


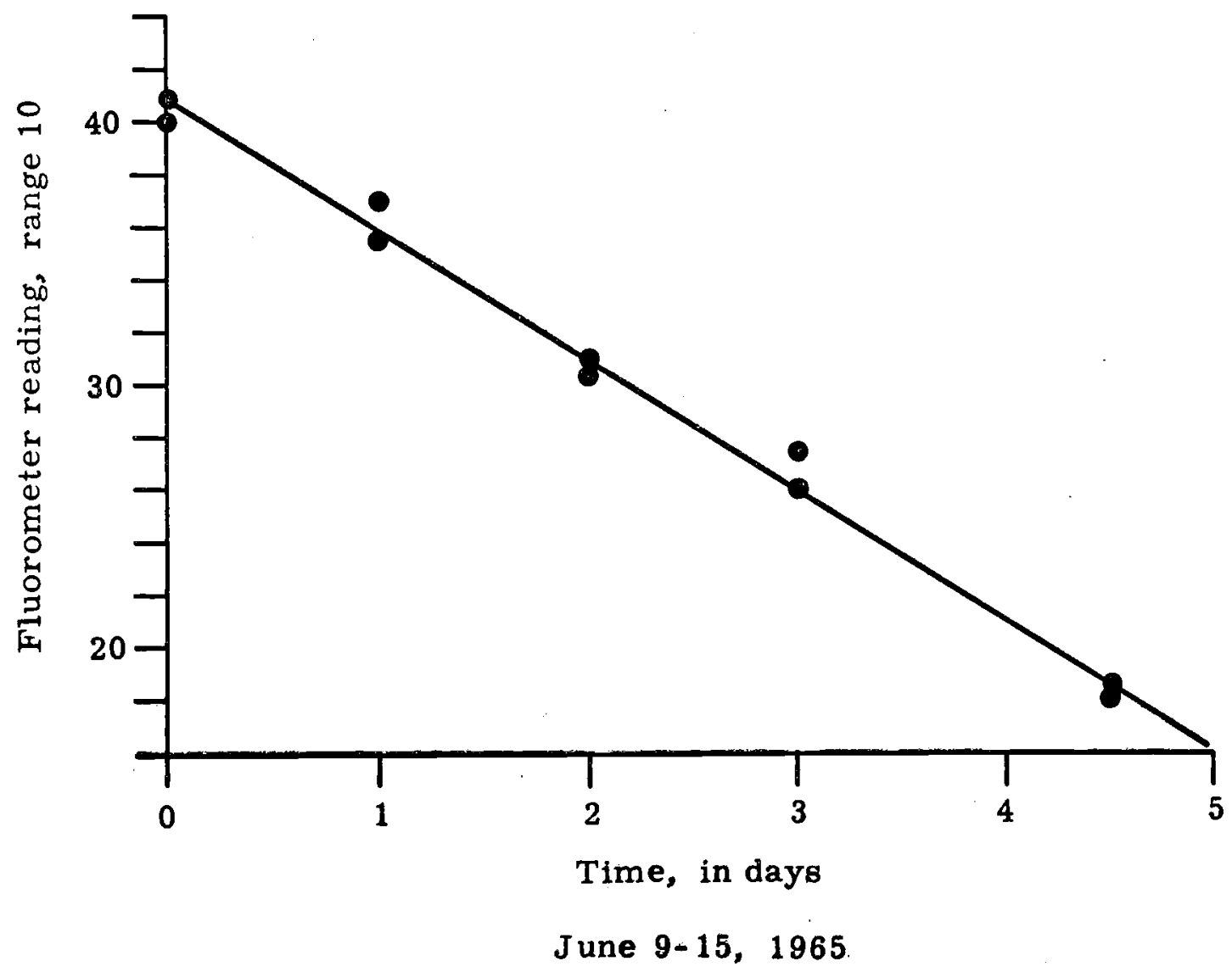

Figure 3. --Variation of fluorescence with exposure to sunlight. 
Brilliant Pontacyl Pink B. The second experiment was similar to the first, except that four standard solutions of differing concentrations$313 \mathrm{ppb}, 156.25 \mathrm{ppb}, 62.6 \mathrm{ppb}$, and $6.26 \mathrm{ppb}$-were used. An attempt also was made to measure the total solar energy absorbed by each sample. Vials were filled with each of the four standard solutions (26 vials of each); a total of 104 vials was used. Four vials of each concentration were stored in the laboratory cupboard in nearly total darkness to calibrate the fluorometer. It is assumed that solutions are stable under these conditions.

The remaining vials were placed in direct sunlight from 0930 to 1530 hours during different days of the test. The cumulative exposure to sunlight was converted to langleys (cal per $\mathrm{cm}^{2}$ ) by consulting records of radiation intensity at the University of Arizona Department of Atmospheric Physics. Figure 4 shows the relation between change in fluorescence and total exposure. It should be noted, however, that the langleys given were measured by a pyrheliometer; therefore, they provide a measure of solar energy absorbed by the samples. The actual energy absorbed by the samples would have to be multiplied by a factor (factor unknown) to account for reflection and absorption of energy by the plastic containers. Unfortunately, the value of this factor is not known. All samples were tested at the same time, after proper fluorometer warmup and temperature stabilization. 


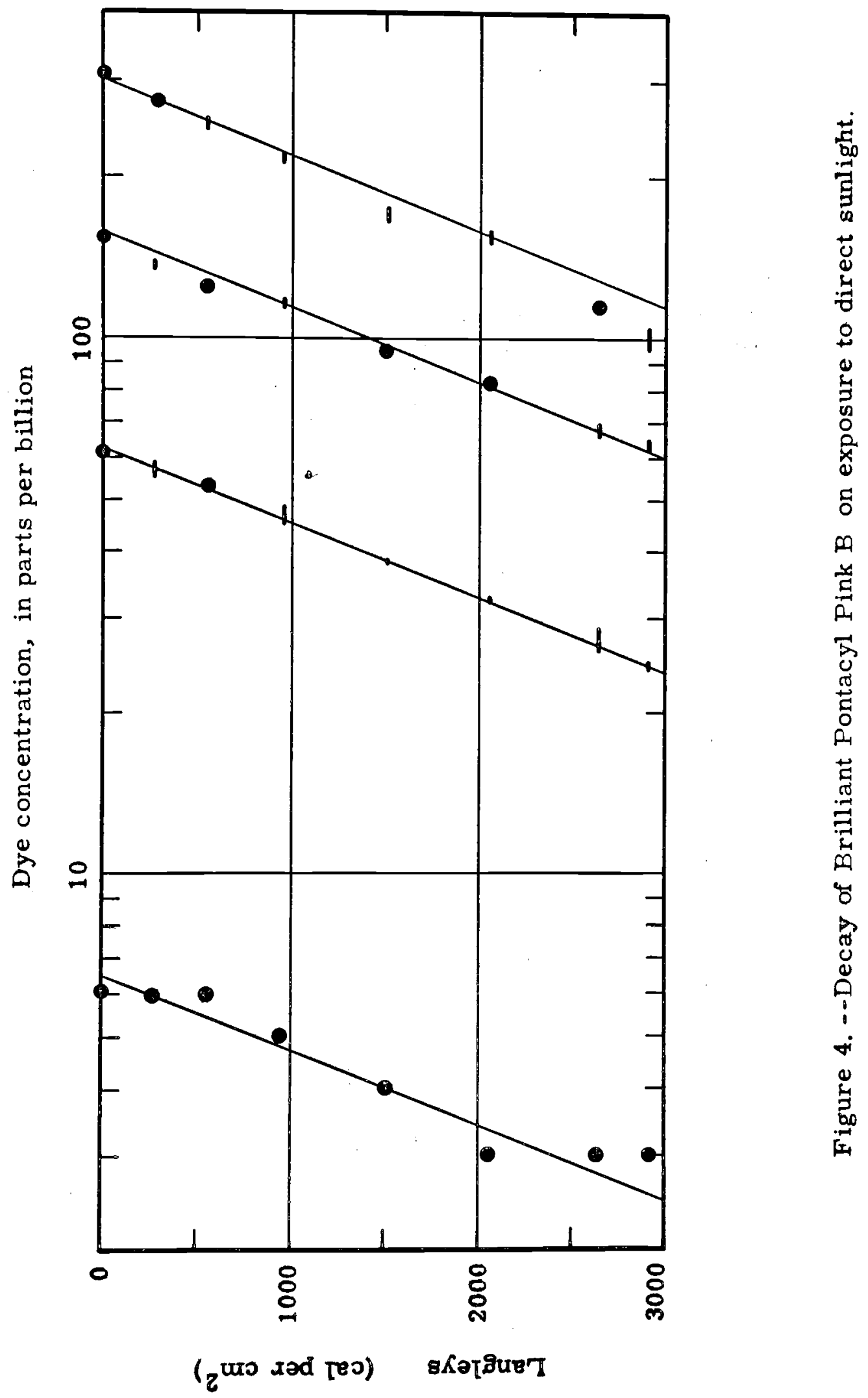


The apparent loss of dye due to photochemical decay may be observed from the fluorometer calibration curve constructed from the standard solutions that remained in the cupboard. All lines on figure 4 are parallel; $313 \mathrm{ppb}$ concentration is somewhat uncertain, however. In each case 50 percent of the original fluorescence was lost after a cumulative exposure of about 2,300 langleys, as recorded by the pyrheliometer。

Since there are about 500 langleys per 6 hours of direct noonday sunlight on a bright January day, we have an apparent half life of fluorescence equal to about 27 hours. By analogy with radioactive decay, we may use the equation

$$
F=F_{O} e^{-x t}
$$

where

$$
\begin{aligned}
& \mathrm{F}=\text { Final concentration; } \\
& \mathrm{F}_{\mathrm{O}}=\text { Initial concentration; } \\
& \mathrm{e}=\mathrm{A} \text { mathematical constant; } \\
& \mathrm{x}=\frac{0.693}{\mathrm{~T}}
\end{aligned}
$$

where

$$
\mathrm{T} \text { = Time of half life; and }
$$

$\mathrm{t}=$ Time during which decay occurred. 
Assuming that 6 hours is the maximum amount of direct sunlight possible in any given test and that the original concentration was $100 \mathrm{ppb}$, we obtain

$$
\begin{aligned}
F & =100 \mathrm{e}^{-\left(\frac{0.693}{27}\right)(6)} \\
& =100 \mathrm{e}^{-.154} \\
& =\frac{100}{\mathrm{e}^{.154}} \\
& =\frac{100}{1.1666} \\
& =95.76
\end{aligned}
$$

which indicates that the maximum percentage of decay for any test is about 14 percent.

\section{Field Experiments}

Four field tests were conducted during this study-Willow Creek test, Sabino Creek test, Paria River test, and Chinle Wash test. Sampling of streamflow for analysis of fluorescent dye was conducted at 2-1/2 minute intervals. The samples were collected in 5-dram clear plastic pharmaceutical dispensary vials. In samples that contained sediment, the vials were allowed to stand until the sediment settled to the bottom; only the clear supernate was fluorometrically tested. Brilliant Pontacyl Pink B tracer was injected using a 
30-gallon Mariotte flask. A small amount of tracer fluid was collected from the flask at the beginning and end of the injection period for testing in the fluorometer to determine if the dye was of equal concentration during the entire test. The fluorometer showed each injection solution to be homogeneous. Current-meter measurements were conducted using the specifications of Corbett and others (1943). The measurements are on file in offices of the U.S. Geological Survey, Water Resources Division, Tucson. The fluorometer readings for all samples and the background fluorescence of each test are given in the appendices. Sampling for background fluorescence was conducted several feet upstream from the injection point at the beginning and end of the injection period. The background fluorescence was constant during each test. Sediment samples were collected using the equipment and methods outlined by the U.S. Inter-Agency Committee on Water Resources (1965) and were analyzed by the Water Resources Division of the U.S. Geological Survey, Tucson. A composite sample was analyzed, and a sieve analysis was conducted to determine sediment size.

\section{Willow Creek Test}

Willow Creek is on the Apache Indian Reservation in Graham County. A preliminary test was conducted on the creek under uniform flow conditions on September 5, 1965. At the time of the test, the 
discharge of the creek was due to pumping-pumpage records indicate that a discharge of $9,200 \mathrm{gpm}(20.49 \mathrm{cfs})$ was maintained throughout the day (fig. 5).

The reach used during the test extends downstream from the pipe outlet for 2.2 miles. Injection took place 50 feet below the pipe outlet (fig. 5A). The tracer was injected at a rate of $13.17 \mathrm{ml}$ per sec for 67 minutes. A 45-minute lapse in injection allowed the streamflow to return to normal fluorescence. The second injection period lasted for 17 minutes, and fluid was injected at a rate of $51.29 \mathrm{ml}$ per sec.

Observers took samples simultaneously $0.3,1.2$, and 2.2 miles downstream from the injection point. Several hundred small wooden blocks were dropped into Willow Creek 15 minutes before the first injection to serve as markers for the observers. Observers counted from the time the blocks were sighted until the sixth $2-1 / 2$ minute interval thereafter, when they filled four vials at equidistant increments across the stream. This procedure was repeated at the twelfth 2-1/2 minute interval, when five vials were filled at equidistant increments. The regular samples were taken throughout this period. The cross-channel sampling was done to check each station for validity of representative samples. The cross-channel sampling also served as a check for homogeneity of dye mixture throughout the stream width at that point. 
FIGURE 5

FLOW IN WILLOW CREEK

\begin{abstract}
A.
Willow Creek diversion from Black River gaging station.

Mariotte flask in place and discharging.
\end{abstract}

B。

Flume used for discharge measurement. Flow from right to left. 

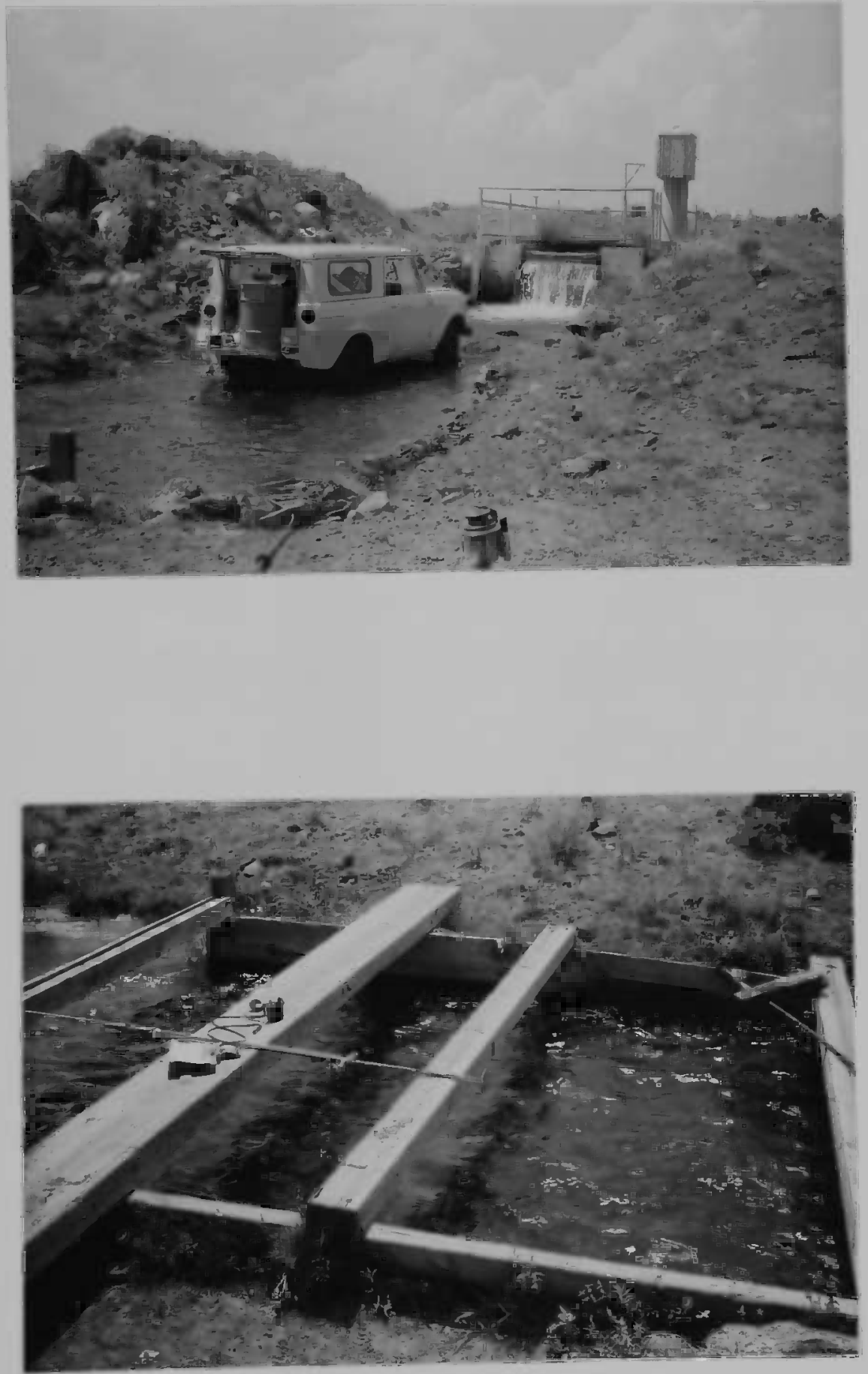

FIGURE 5 
The recorder chart from the U.S. Geological Survey gaging station at the pipe outlet is shown in figure 6 . The slight variation in stage indicates essentially constant discharge. A current-meter measurement was made during the first injection period, and showed a discharge of $20.03 \mathrm{cfs}$. The sediment concentrations of Willow Creek was extremely low during the test, and the flow appeared crystalclear. Results of the dye-dilution test are shown in Appendix A. For the first injection period, a discharge of $20.24 \mathrm{cfs}$ was calculated from the plateau of the uppermost sampling site.

The fluorometer dial readings versus time for each site were plotted. The areas under the respective curves were determined and are as follows:

\begin{tabular}{ccc} 
Site & Dial-minutes & $\begin{array}{c}\text { Parts per billion } \\
\text { fluorescence- } \\
\text { minutes }\end{array}$ \\
\cline { 2 - 3 } 1 & $2,453.25$ & 921.69 \\
2 & $2,447.00$ & 919.34 \\
3 & $2,447.56$ & 919.55
\end{tabular}

The percent variation of the extremes (Sites 1 and 2) varies by only 0.26 percent. Therefore, the loss of dye by adsorption was very slight during this experiment; any loss would have been reflected in a decrease in area under the curve for each site downstream. 


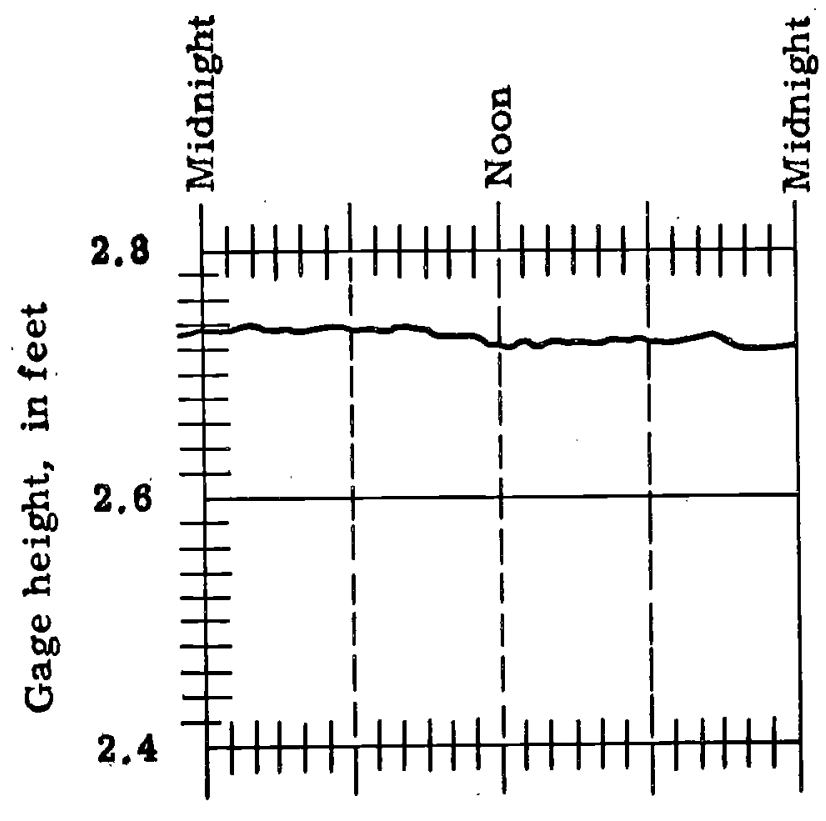

Time, in hours

September 5, 1965

Figure 6. - Recorder chart from Willow Creek diversion of Black River gaging station. 
Inasmuch as the discharge of Willow Creek was constant, analysis of the test is possible by the total-recovery method. This method is used where a "slug" of dye is injected into the stream, and the dye cloud is monitored downstream. The theory of the method does not require that the dye be injected instantaneously. The following equation is applicable:

$$
Q=\frac{V_{T} C_{1}}{\int_{0}^{\infty}\left(C_{2}-C_{0}\right) d t}
$$

where

$$
\begin{aligned}
& V_{T}=\text { The volume of dye solution injected into the } \\
& \text { stream; } \\
& \mathrm{C}_{1}=\text { The concentration of injection solution; } \\
& \mathrm{C}_{2}=\text { The concentration of streamflow (variable) } \\
& \text { after the injection fluid is homogeneously } \\
& \text { mixed across the stream section; } \\
& \mathrm{C}_{\mathrm{O}}=\text { The natural fluorescence background of the } \\
& \text { streamflow; and } \\
& \int_{0}^{\infty}\left(\mathrm{C}_{2}-\mathrm{C}_{\mathrm{O}}\right) \mathrm{dt}=\text { The total area under the concentration-time } \\
& \text { curve. }
\end{aligned}
$$

Applying equation (10) to data from the upper site, the first part of the Willow Creek test, where the injection rate using the Mariotte flask was $13.17 \mathrm{ml}$ per sec: 


$$
\mathrm{V}_{\mathrm{R}}=13.17 \mathrm{ml} \text { per } \mathrm{sec}
$$

where

$$
V_{R}=\text { Volume-rate of injection, }
$$

so

or

$$
\begin{aligned}
V_{R} & =0.013171 \text { per sec, } \\
V_{R} & =(0.01317)(0.03531) \\
& =0.00046503 \mathrm{cfs}
\end{aligned}
$$

Injection was continued for 67 minutes $(4,020$ seconds).

$$
\begin{aligned}
V_{\mathrm{T}} & =(0.000465031)(4020) \\
& =1.86943 \mathrm{ft}^{3}
\end{aligned}
$$

The concentration of the injection fluid was determined to be $335,140 \mathrm{ppb}$.

Thus:

$$
\begin{aligned}
\mathrm{V}_{\mathrm{T}_{1} \mathrm{C}_{1}} & =(1.86943)(335,140) \\
& =626,521.26 \mathrm{ppb \textrm {ft } ^ { 3 }}
\end{aligned}
$$

The fluorometer readings from time 1115 to 1315 were plotted and a smooth curve was passed through the points. (See Appendix A.) From this curve, fluorometer readings were selected at 1.25-minute increments. Using the fluorometer calibration curve, each fluorometer reading was converted to parts per billion. Thus, by the histogram method, the area under the curve is $29,700 \mathrm{ppb} \mathrm{sec}$. Using this figure and substituting equation (11) into equation (10), we obtain: 


$$
\begin{aligned}
& Q=\frac{626,521}{29,700} \\
& Q=21.09 \mathrm{cfs}
\end{aligned}
$$

The larger discharge indicated by the total-recovery method may be due to a slight inaccuracy in determining the area under the concentration-time curve or to the possible loss by sorption of dye on the leading front of the initial dye cloud.

\begin{tabular}{|c|c|c|c|}
\hline Measuring method & $\begin{array}{l}\text { Discharge } \\
\quad(\mathrm{cfs})\end{array}$ & $\begin{array}{c}\text { Variation from } \\
\text { current-meter } \\
\text { measurement } \\
\text { (percent) }\end{array}$ & $\begin{array}{l}\text { Variation } \\
\text { from dye- } \\
\text { dilution test } \\
\text { (percent) }\end{array}$ \\
\hline Pumping station & 20.49 & +2.3 & +2.2 \\
\hline Current meter & 20.03 & 0.0 & -1.0 \\
\hline Dye dilution & 20.24 & +1.1 & 0.0 \\
\hline Total recovery & 21.09 & +5.3 & +4.0 \\
\hline
\end{tabular}

Results of the Willow Creek test are as follows:

Sabino Creek is in the Coronado National Forest, Pima County. A test was made on the creek under nonuniform flow conditions on November 25, 1965.

The reach used extends 0.85 mile downstream from the lower stream crossing on upper Sabino Canyon Drive. The lower end of the 
reach is marked by a Survey gaging station cableway located about 300 feet downstream from the gaging station. Injection was made at the crossing at a rate of $13.17 \mathrm{ml}$ per sec. Samples were taken beneath the cableway.

The recorder chart from the gaging station is shown in figure 7.

Three current-meter measurements were made during the test under the cableway (fig. 8):

$\begin{array}{cc}\begin{array}{c}\text { Mean time of the } \\ \text { measurement }\end{array} & \begin{array}{c}\text { Computed discharge } \\ \text { (cfs) }\end{array} \\ 2110 & 220 \\ 2320 & 148 \\ 0040 & 118\end{array}$

The sediment concentration was very low, and the flow was clear and clean on visual inspection. Results of the dye-dilution test are shown in Appendix B. The discharge determined by the second current-meter measurement was $148 \mathrm{cfs}$ compared with a discharge of $141 \mathrm{cfs}$ by the dye-dilution method. Discharge by the dye-dilution method was 4.7 percent below that given by the current-meter measurement (table 1)。 


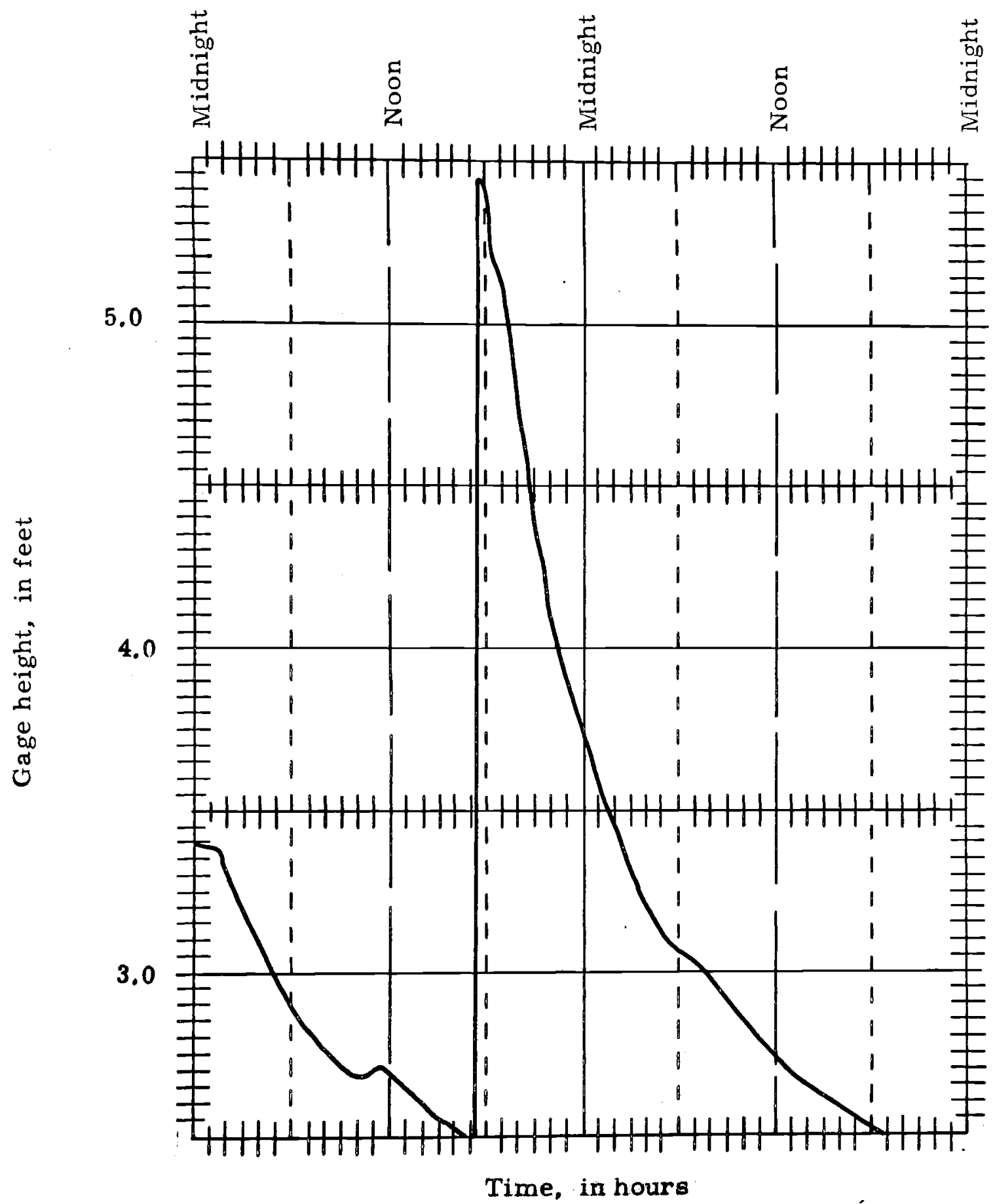

November 25, 1965

November 26, 1965

Figure 7. --Recorder chart from Sabino Creek gaging station. 


\section{FIGURE 8}

\section{FLOW IN SABINO CREEK}

A.

Dye injection site for Sabino Creek test.

B.

Dye sampling and current-meter-measurement site for Sabino Creek test. 

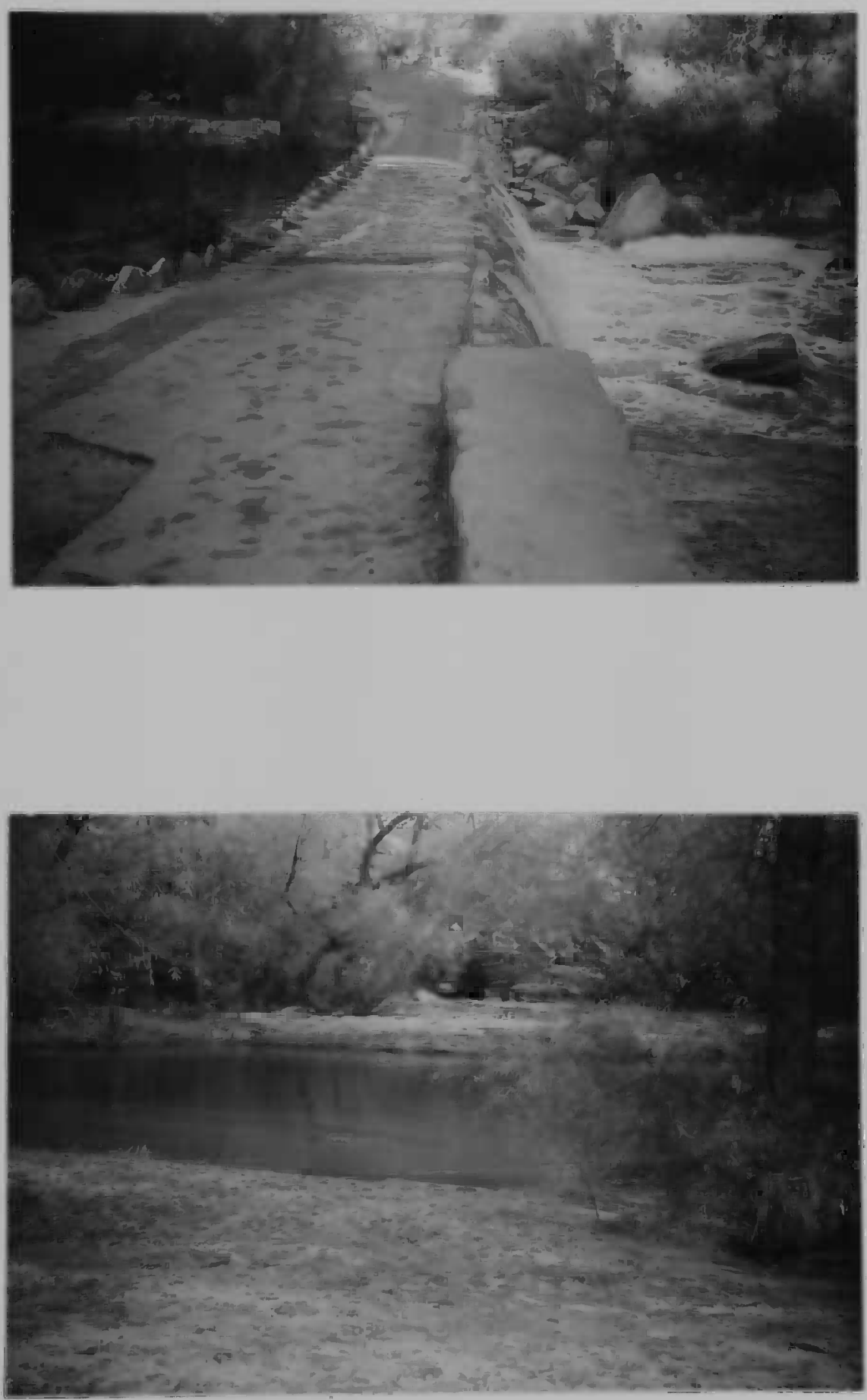

FIGURE 8 


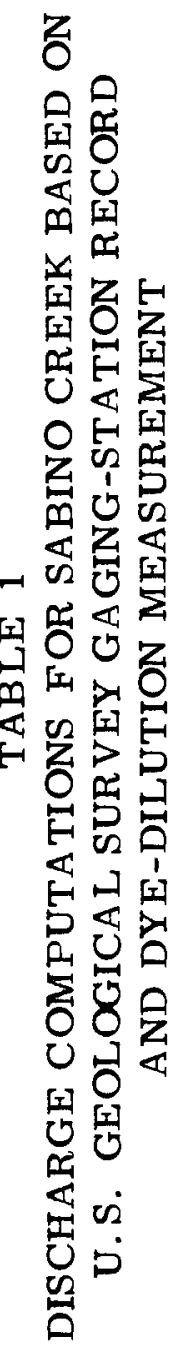

\begin{tabular}{|c|c|c|c|c|c|c|c|}
\hline \multicolumn{2}{|c|}{ 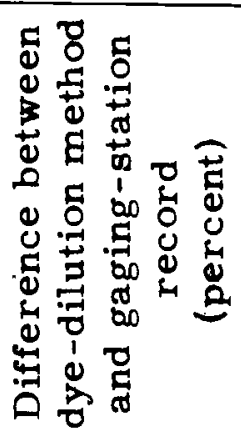 } & $\stackrel{7}{0}$ & $\ddot{0}$ & $\stackrel{5}{5}$ & $\begin{array}{l}\infty \\
+ \\
1\end{array}$ & $\begin{array}{l}\vec{i} \\
1\end{array}$ & $\stackrel{0}{0}$ \\
\hline & 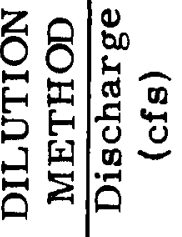 & $\stackrel{\infty}{\underset{1}{\sim}}$ & $\stackrel{10}{\ddagger}$ & $\underset{\mathcal{F}}{\mathcal{F}}$ & $\stackrel{P}{\Psi}$ & $\stackrel{\infty}{\sim}$ & $\tilde{m}$ \\
\hline \multirow{4}{*}{ 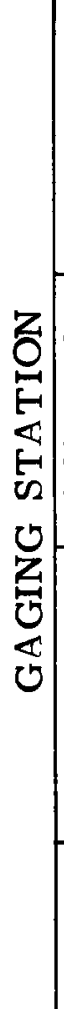 } & 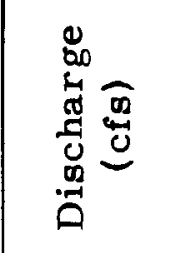 & $\mathscr{0}$ & is & in & $\tilde{ \pm}$ & $\exists$ & $\stackrel{\sim}{\sim}$ \\
\hline & 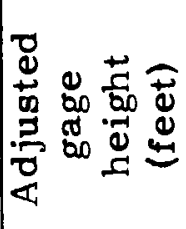 & $\begin{array}{l}\dot{m} \\
\dot{m}\end{array}$ & $\begin{array}{l}\text { mे } \\
\text { m. }\end{array}$ & $\begin{array}{l}\dot{m} \\
\text { in }\end{array}$ & $\begin{array}{l}\stackrel{D}{N} \\
\dot{m}\end{array}$ & $\begin{array}{l}\stackrel{M}{N} \\
\dot{m}\end{array}$ & $\begin{array}{l}\frac{\sigma}{1} \\
\dot{m}\end{array}$ \\
\hline & 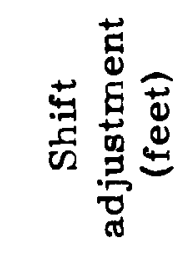 & $\begin{array}{l}\infty \\
m \\
0 \\
\dot{1}\end{array}$ & $\begin{array}{l}\infty \\
m \\
0 \\
i\end{array}$ & $\begin{array}{l}\infty \\
m \\
0 \\
i\end{array}$ & $\begin{array}{l}\infty \\
m \\
0 \\
i\end{array}$ & $\begin{array}{l}\infty \\
m \\
0 \\
0\end{array}$ & $\begin{array}{l}\infty \\
m \\
0 \\
i\end{array}$ \\
\hline & 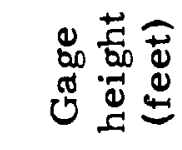 & i & $\stackrel{N}{i}$ & $\begin{array}{l}\infty \\
0 \\
\text { in }\end{array}$ & $\begin{array}{l}\Xi 0 \\
\text { in }\end{array}$ & $\begin{array}{l}8 \\
\text { in }\end{array}$ & $\begin{array}{l}\text { is } \\
\text { in }\end{array}$ \\
\hline & 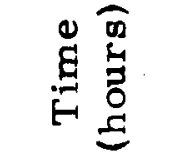 & 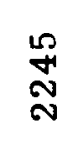 & 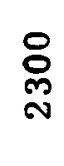 & $\stackrel{10}{n}$ & 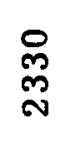 & 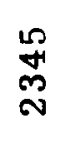 & $\underset{N}{\stackrel{O}{+}}$ \\
\hline
\end{tabular}




\section{Paria River Test}

The Paria River is in Coconino County。 A test was conducted on the river on April 3,1966, to determine the validity of the dyedilution method in sediment-1aden streams.

The reach used during the test was the 1.5 miles above the junction of the Paria and Colorado Rivers. Injection took place at the upper end of the reach. The tracer was injected at a rate of $4.22 \mathrm{ml}$ per sec for 2 hours and 20 minutes (fig. 9).

Observers took samples 0.4 and 1.2 miles downstream from the injection site. The recorder chart from the U.S. Geological Survey gaging station 0.2 mile downstream from the injection site is shown in figure 10.

At the lower site, the data obtained by the dye-dilution test were erroneous, because the station was too close to the Colorado River. The Colorado River flow increased during the test, and the observer reported an increase in stage of the Paria at the sampling site. The evidence suggests that backwater conditions from the Colorado River affected the data obtained from the lower sampling site.

In the Paria River test, an unusual degree of scatter of the data is evident, which is probably due to slight contamination of the samples after an accident with the Mariotte flask in transport. Fluid spilled from the tank resulted in the staining of the cardboard 


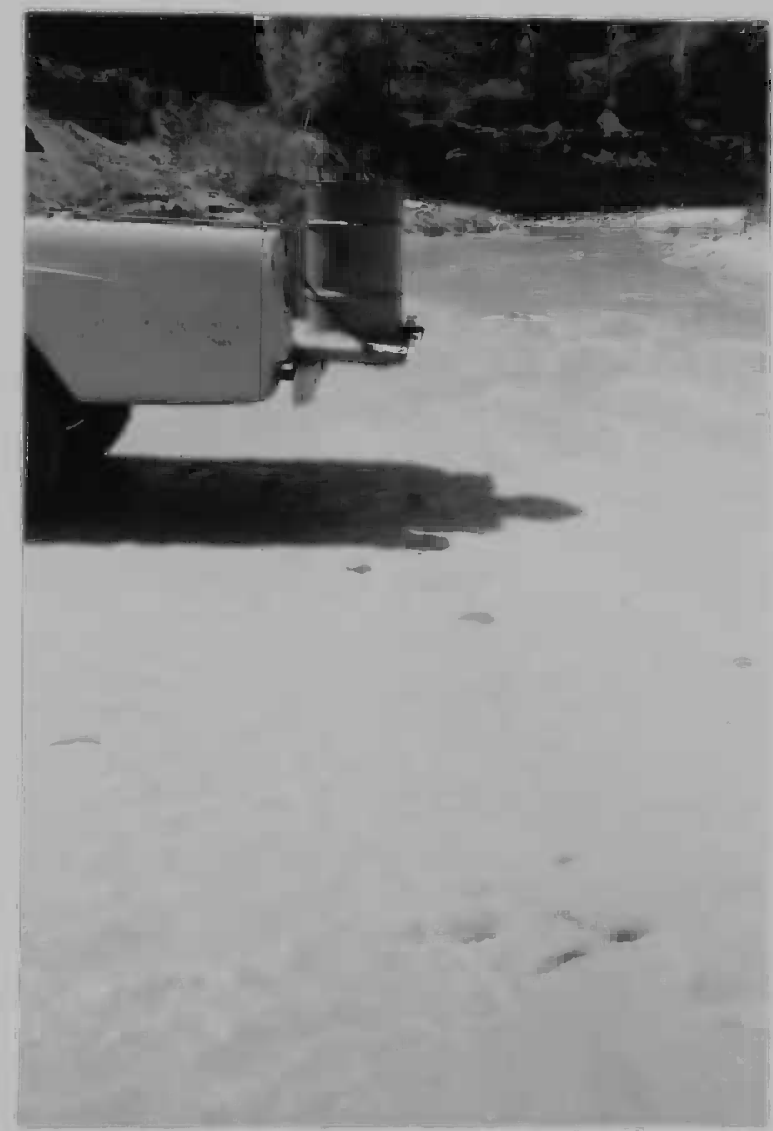

FIGURE 9

DYE INJECTION AT THE UPPER END OF THE PARIA RIVER TEST REACH 


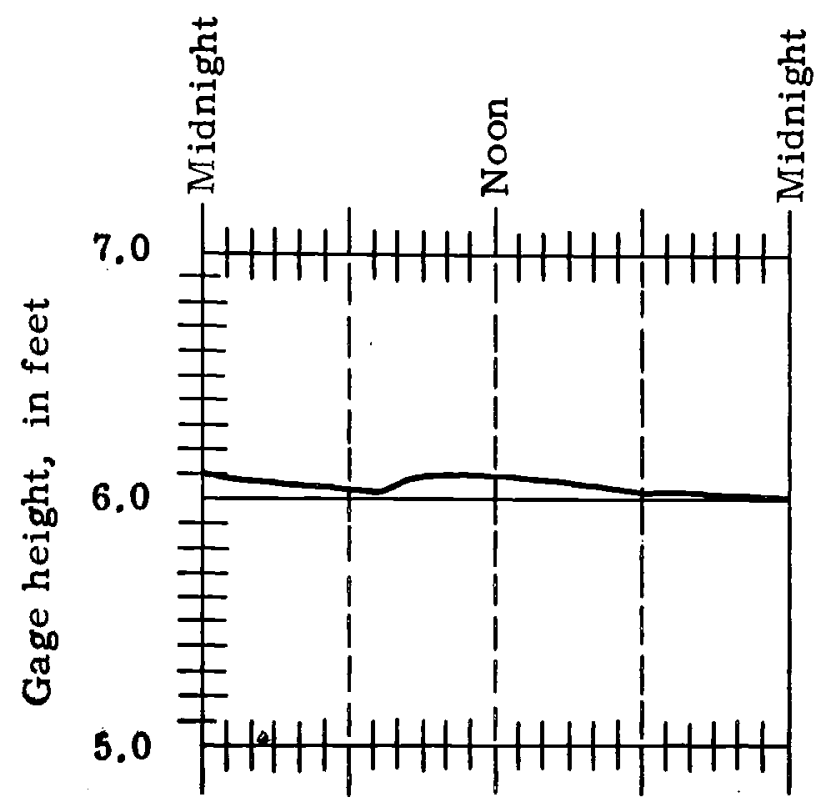

Time, in hours

April 3, 1966

Figure 10.--Recorder chart from Paria River gaging station. 
containers in which the new and unused sampling vials were stored。 Special care, however, was exercised by the sampling personnel to avoid vial contamination. Results of the test data show a slight random distribution which may be due to (1) sample contamination due to the accident, (2) the sediment load of the stream, and (3) variation of background due to differences in sediment in the vials at the time of fluorometer analysis.

Two current-meter measurements were made in order to compare the amount of discharge given by the current meter with the amount given by the dye-dilution method. The first current-meter measurement was made at the point of dye injection $(8.79 \mathrm{cfs})$ and the second was made at the upper sampling site $(7.85 \mathrm{cfs})$. It was neces sary to extend the dye-dilution data to the time of the current-meter measurement. The data were extended by drawing a straight line through the mean of the data points, which represent instantaneous stream fluorescence. The time interval for the points used was from 1205 to 1330 hours. Three sediment samples were taken 50 feet upstream from the injection site. The sediment load was $1,470 \mathrm{ppm}$ by weight; 99.8 percent of the sediment was finer than $0.053 \mathrm{~mm}$. The results of the dye-dilution test are shown in Appendix $\mathrm{C}$ and are compared with the current-meter measurement below: 


\begin{tabular}{ccc} 
Measuring method & $\begin{array}{c}\text { Discharge } \\
(\mathrm{cfs})\end{array}$ & $\begin{array}{c}\text { Variation from } \\
\text { current-meter } \\
\text { measurement } \\
\text { (percent) }\end{array}$ \\
\cline { 2 - 3 } Current meter & 7.85 & 0.0 \\
Dye dilution & 8.71 & +11.0
\end{tabular}

Chinle Wash Test

Chinle Wash is in Apache County. A second test on sedimentladen streams was conducted on April 10, 1966.

The reach used during the test extends 1.2 miles downstream from the bridge on Arizona Highway 64. Injection took place beneath the bridge at a rate of $4.22 \mathrm{ml}$ per sec for 4 hours.

The observer took samples 1.2 miles downstream from the bridge. The recorder chart from the U.S. Geological Survey gaging station 100 feet upstream from the bridge is shown in figure 11, and the results of the dye-dilution test are given in Appendix D.

A current-meter measurement was made 160 feet upstream from the bridge and showed a discharge of $2.68 \mathrm{cfs}$. The sediment load was 3,720 ppm by weight, and 99.9 percent of the sediment was finer than $0.053 \mathrm{~mm}$.

A direct comparison of discharge computed from the currentmeter measurement with discharge computed from the dye-dilution 


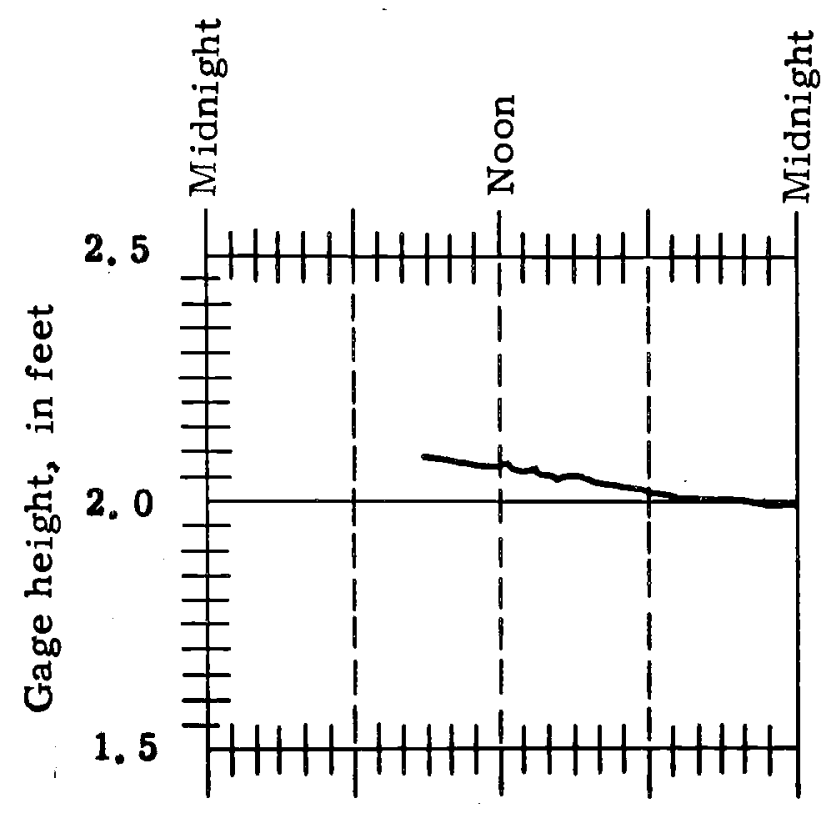

Time, in hours

April 10, 1966

Figure 11.--Recorder chart from Chinle Wash gaging station. 
method is not possible. The current-meter measurement was conducted at the injection point rather than at the sampling site. Therefore, a direct comparison of the two means of stream measurement would require a time adjustment of the mean time of the current-meter measurement so that it would apply to the same stream discharge at the sampling site. The fact that the mean time of the current-meter measurement was 55 minutes after the start of injection is of no help, because the sampling site was chosen arbitrarily and has no rating relation with the gaging station, and the staff or river stage was not recorded at the sampling site.

This test shows the importance of taking samples and currentmeter measurements at the same location. If the purpose of a dyedilution test is the rating of a gaging station, the sampling site must be close to the gaging station.

Because the scatter of data points was small in spite of the high suspended-sediment concentration during the Chinle Wash test, it seems likely that the scatter in the Paria River test was due to causes other than suspended-sediment concentration.

Discharge as determined by the dye-dilution method ranged from 2.40 to $4.00 \mathrm{cfs}$. 


\section{DISCUSSION AND SUMMARY}

\section{Possible Sources of Error}

If systematic errors are disregarded, the mean of errors in current-meter measurements is random and is normally distributed (Carter and Anderson, 1963, p. 106). The same is assumed true for fluorometer operation, but not for the dye-injection method as a whole. Dye adsorption onto organic or inorganic substances and fluorescence breakdown of the dye with exposure to light reduce the magnitude of fluorescence recovered in the sampling procedure. The loss results in departure from the theory used in the dye-injection method. Because the degree of fluorescence is inversely proportional to discharge, the mean of the errors involved in the dye-dilution method will result in some plus value-i. e., the dye-dilution method will tend to overestimate the true or exact discharge.

This study indicates that collectively the errors are very minor. Although no sediment was present in the flow of Willow Creek, the homogeneous dye solution was in contact with the stream channel for 2.2 miles. Several varieties of grass in large stands occur in and along the channel. Willow Creek is at an altitude of 5,975 feet, where 
there was direct noonday sunlight during the early hours of the test. At this altitude, the sunlight should contain considerable ultraviolet rays. Although the rays may be responsible for fluorescence decay of the dye the Willow Creek test showed no measureable adsorption or fluorescent decay. Therefore, for practical purposes the plus mean error for dye-dilution tests is negligible.

-It is suspected that different organic and inorganic substances will exhibit slightly different affinities for dye adsorption and absorption. Conducting the dye-injection test at night eliminates the fluorescence-decay factor; however, floods occur anytime, and the user of automated dye-injection tests must consider this possibility.

Dye manufacturers are engaged in research to develop dyes that will reduce the properties of sorption and light decay present in current products.

The deviation between computed discharge by the currentmeter method and computed discharge by the dye-dilution method does not always indicate error in the latter method. Computation of discharge using the Price current meter utilizes the following equation:

$$
Q=V A
$$

where

$Q=$ discharge, in cubic feet per second; 
$\mathrm{V}=$ velocity, in feet per second; and

$A=$ area, in square feet.

Equation (12) allows the computation of the rate of discharge of water in clear streams. Suspended sediment in a stream will occupy a certain percent of the stream area, and the computed value of $Q$ will no longer represent the flow of water alone. Normally, this factor is ignored, because of the extremely low-sediment concentrations in most streams. Even sediment loads that are termed "heavy" normally do not consist of concentrations large enough to cause an error of a magnitude that would equal the error of a current-meter measurement. In the Southwest, however, sediment loads at high stage rival World records for suspended-sediment concentrations. In some northern Arizona streams, as much as 20 percent of the volume of streamflow is occupied by sediment $(600,000 \mathrm{ppm}$ by weight). Therefore, this factor should be considered when comparing current-meter measurements and dye-dilution measurements made on streams with high suspended-sediment concentrations.

\section{$\underline{\text { Future Uses }}$}

The greatest potential afforded by the dye-dilution method of computing flow is in the rating of different types of surface-water stations. In this regard, the dye-dilution method may be utilized in 
conjunction with slope-area measurements; where difficulty in acquiring slope-area measurements is encountered, it alone may be used. Where dye injection and sampling are continuous for the duration of flow, the dye-dilution method offers a direct method for determining total discharge. This approach offers great promise for flashflood studies in the Southwest, where station ratings have not been established. The dye-dilution method especially lends itself to studies involving a water budget.

Continuous injection and sampling will allow a hysteresis analysis of flood hydrographs and will provide both the rating for peak discharge and the total discharge. Storm hydrographs typically show very steep rising limbs and more extended recession limbs. Most current-meter measurements are made at peak discharge or on the recession limb of the hydrograph. In many instances, this is due to the lack of flood warnings, which prevent personnel from being at the site and ready to take measurements when flow begins. However, rising stages typically carry huge quantities of debris, which make current-meter measurement difficult or impossible. As a result, few current-meter measurements exist for the rising limb of hydrographs。 Even if a current-meter measurement is obtained on the rising limb of a hydrograph, another problem is encountered in the computation of the measurement. The very rapid change in river stage during measurement requires that the computed gage height be weighted. 
This weighting reduces the accuracy of the gage-height value assigned to the measurement. Therefore, the evaluation of the hysteresis effect of rating curves for different stations is impossible or produces questionable results. The dye-dilution method, however, may allow this evaluation.

Before using the dye-dilution method for evaluation of the hysteresis effect, however, the following factors must be considered. During the rising limb of the hydrograph, water enters the streambank and forms bank storage. If a dye-dilution measurement is in progress, the dye concentration in this water will be dependent on the rate of discharge. As discharge increases, dye concentration decreases, at the same time that more water is lost to bank storage. Thus the dye concentration of the water in bank storage will vary. As discharge decreases, water will be released from bank storage but at a different rate than that at which it entered; also, the total volume of water released will be less than the volume stored. The dye concentration in the water released from bank storage will be of a different magnitude than that of the river water. The above factors would complicate any analysis. Fortunately, in most cases these effects may be neglected without significantly affecting the accuracy of the discharge calculation. 


\section{Future Developments}

U.S. Geological Survey personnel are, at the present time, involved in studies to determine the applicability of the dye-dilution method in measuring streamflow under different conditions and in different localities. The Survey is developing apparatus designed to inject and sample automatically when triggered by streamflow. Major factors in the consideration of automatic apparatus are the initial expense, simplicity of operation, and physical size. The withdrawal of a discrete dye sample at short time intervals will be necessary. In streams in the Southwest, sampling must begin at or near zero flow and continue for the duration of flow. The method will provide data for rating the station at all river stages during the test, and total discharge also may be computed.

\section{Conclusion}

The feasibility of conducting discharge measurements by the dye-dilution method has been examined by laboratory and field experiments. The direct comparison of discharge computed from the currentmeter measurement and computed from the dye-dilution method was possible in three field tests. The maximum deviation between the two methods was 11 percent. This percentage contains possible errors in the current-meter measurement and the dye-dilution method. The 
figure corresponds favorably with the computed discharge from gaging stations on sand-channel streams. For a slope-area measurement, 15 percent accuracy is considered near optimum. Therefore, the conclusion is made that computation of streamflow by the dye-dilution method holds promise for gaging streams in the Southwest. Such measurements fall well within the acceptable limits of accuracy. 


\section{APPENDIX A-WILLOW CREEK TEST}

Fluorometer calibration: $34 \mathrm{ppb}=90.5$ on fluorometer dial.

Injection solution $=335,140 \mathrm{ppb}$.

Injection rate $=13.17 \mathrm{ml}$ per sec.

Discharge obtained by current-meter measurements is listed as CMIM.

A background of 1.0 dial units has been removed from the following data.

\begin{tabular}{ccc} 
Time & $\begin{array}{c}\text { Fluorometer } \\
\text { reading }\end{array}$ & Discharge \\
(hours) & (dial units) & (cfs) \\
\hline
\end{tabular}

(Upper station)

1115

0.0

0.5

0.0

0.0

0.0

2.5

1130

2.5

6.0

13.5

17.0

19.0

20.03 CMIM

19.5

1145

19.5

20.0

20.5

20.0

20.24

20.5

20.24

20.5

20.24 
Time

(hours)

1200

1215

1230

1245

1300

1315

Fluorometer

reading

(dial units)

20.5

20.5

20.5

20.5

20.5

20.5

20.5

20.5

20.5

20.5

20.0

20.0

20.5

20.5

17.5

8.5

4. 5

2.0

1.5

1.0

0.5

0.5

0.5

0.5

0.5

0.5

0.0

0.5

0.0

0.5

0.0

0.0

0.0

0.5

26.0

53.5
Discharge

(cfs)

20.24

20.24

20.24

20.24

20.24

20.24

20.24

20.24

20.24

20.24 
Time

(hours)

1330

1345

1400

1200

1215

1230
Fluorometer

\begin{tabular}{cc}
$\begin{array}{c}\text { reading } \\
\text { (dial units) }\end{array}$ & $\begin{array}{c}\text { Discharge } \\
\text { (cfs) }\end{array}$ \\
\hline
\end{tabular}

66.5

66.5

67.5

67.5

53.5

26.5

13.5

7.0

5.0

3.0

1.5

1.0

0.5

0.0

0.0

0.0

(Middle station)

0.0

0.0

0.0

0.0

0.0

0.5

1.5

3.0

4.5

8.0

10.5

12.5

14.5

15. 5

16. 5

17.0

18.0

18.5 


\begin{tabular}{|c|c|c|}
\hline $\begin{array}{c}\text { Time } \\
\text { (hours) }\end{array}$ & $\begin{array}{c}\text { reading } \\
\text { (dial units) }\end{array}$ & $\begin{array}{c}\text { Discharge } \\
\text { (cfs) }\end{array}$ \\
\hline \multirow[t]{6}{*}{1245} & 18.5 & \\
\hline & 19.0 & \\
\hline & 19.0 & \\
\hline & 19.0 & \\
\hline & 19.0 & \\
\hline & 19.5 & 21.28 \\
\hline \multirow[t]{6}{*}{1300} & 19.5 & 21.28 \\
\hline & 19.5 & 21.28 \\
\hline & 19.5 & 21.28 \\
\hline & 19.5 & 21.28 \\
\hline & 19.5 & 21.28 \\
\hline & 19.5 & 21.28 \\
\hline \multirow[t]{6}{*}{1315} & 20.0 & \\
\hline & 19.5 & 21.28 \\
\hline & 19.0 & \\
\hline & 16.5 & \\
\hline & 13.5 & \\
\hline & 11.0 & \\
\hline \multirow[t]{6}{*}{1330} & 8.5 & \\
\hline & 6.5 & \\
\hline & 5.5 & \\
\hline & 4.5 & \\
\hline & 3.5 & \\
\hline & 3.0 & \\
\hline \multirow[t]{6}{*}{1345} & 2.5 & \\
\hline & 2.0 & \\
\hline & 1.5 & \\
\hline & 1.5 & \\
\hline & 1.0 & \\
\hline & 1.0 & \\
\hline \multirow[t]{6}{*}{1400} & 0.5 & \\
\hline & 0.5 & \\
\hline & 1.5 & \\
\hline & 4.5 & \\
\hline & 8.5 & \\
\hline & 22.5 & \\
\hline
\end{tabular}


Time

(hours)

1415

1430

1445

1500

1515

1300
Fluorometer

\begin{tabular}{cc} 
reading & Discharge \\
(dial units) & (cfs) \\
\hline
\end{tabular}

33.5

42.5

52.5

51.0

48.0

42.5

34.0

26.0

19.5

15.0

12.5

10.0

8. 0

6.5

5. 5

4. 5

3.5

2. 5

2. 0

1. 5

1. 0

0.5

0.5

0.0

0.0

(Lower station)
0.0
0.0
0.5
1. 0
1. 5
2.5 
Time

(hours)

1315

1330

1345

1400

1415

1430

\section{Fluorometer}

$$
\text { reading }
$$

(dial units)

Discharge

Ycfs)

4. 0

5.0

6.5

8.0

8.5

10.0

11.0

12.5

14.5

13.5

14.5

15.0

15.5

16.0

16.5

16.5

16.5

16.5

17.0

17.0

17.0

19.5

18.0

17.5

16.5

15.5

14.5

13.0

11.5

10.5

9.5

8.0

7.5

6.5

6.0

5. 5 
Fluorometer

Time

(hours)

1445

1500

1515

1530

1545

1600 reading

(dial units)

4. 5

4.0

4.0

3.5

3.5

3.5

5.5

8.0

11.5

17.0

23.0

28.0

32.5

--

$-$

33.5

31.0

28.5

24.5

21.5

19.5

16.5

14.5

12.5

11.0

9.5

8.5

7.5

7.0

6.5

5.5

5.0

4. 5

4. 0

3.5

3.0
Discharge

(cfs) 


\begin{tabular}{|c|c|c|}
\hline $\begin{array}{c}\text { Time } \\
\text { (hours) }\end{array}$ & $\begin{array}{c}\text { Fluorometer } \\
\text { reading } \\
\text { (dial units) }\end{array}$ & $\begin{array}{c}\text { Discharge } \\
\text { (cfs) }\end{array}$ \\
\hline 1615 & $\begin{array}{l}2.5 \\
2.5 \\
2.0 \\
2.0 \\
-- \\
1.5\end{array}$ & \\
\hline 1630 & $\begin{array}{l}1.5 \\
1.0\end{array}$ & \\
\hline 1645 & 0.0 & \\
\hline
\end{tabular}




\section{APPENDIX B - SABINO CREEK TEST}

Fluorometer calibration: $9.5 \mathrm{ppb}=25$ on fluorometer dial.

Injection solution $=2,730,000 \mathrm{ppb}$.

Injection rate $=13.17 \mathrm{ml}$ per sec.

A smooth curve was passed through the plotted curve of the fluorometer reading versus time. The value in the "Average" column was taken from this curve.

Discharge obtained by current-meter measurements is listed as CMM.

A background of 1.0 dial units has been removed from the following data.

\begin{tabular}{|c|c|c|c|}
\hline $\begin{array}{c}\text { Time } \\
\text { (hours) }\end{array}$ & $\begin{array}{l}\text { Fluorometer } \\
\text { reading } \\
\text { (dial units) }\end{array}$ & $\begin{array}{c}\text { Average } \\
\text { (dial units) }\end{array}$ & $\begin{array}{c}\text { Discharge } \\
\text { (cfs) }\end{array}$ \\
\hline \multirow[t]{6}{*}{2145} & 0.0 & & \\
\hline & 0.5 & & \\
\hline & 0.0 & & \\
\hline & 0.0 & & \\
\hline & 0.5 & & \\
\hline & 1.5 & & \\
\hline \multirow[t]{6}{*}{2200} & 3.5 & & \\
\hline & 6.5 & & \\
\hline & 7.5 & & \\
\hline & 11.5 & & \\
\hline & 12.0 & & \\
\hline & 16.0 & & \\
\hline
\end{tabular}




\begin{tabular}{|c|c|c|c|}
\hline $\begin{array}{l}\text { Time } \\
\text { (hours) }\end{array}$ & $\begin{array}{l}\text { Fluorometer } \\
\text { reading } \\
\text { (dial units) } \\
\end{array}$ & $\begin{array}{c}\text { Average } \\
\text { (dial units) }\end{array}$ & $\begin{array}{c}\text { Discharge } \\
\text { (cfs) }\end{array}$ \\
\hline \multirow{6}{*}{2215} & 18.5 & & \\
\hline & 20.0 & & \\
\hline & 20.5 & & \\
\hline & 20.5 & & \\
\hline & 21.0 & & \\
\hline & 21.0 & & \\
\hline \multirow[t]{6}{*}{2230} & 21.5 & 22.0 & 151.9 \\
\hline & 21.5 & 22.1 & 151.2 \\
\hline & 22.5 & 22.2 & 150.6 \\
\hline & 22.5 & 22.3 & 150.0 \\
\hline & 22.0 & 22.4 & 149.4 \\
\hline & 22.5 & 22.5 & 148.5 \\
\hline \multirow[t]{6}{*}{2245} & 23.5 & 22.6 & 148.0 \\
\hline & 22.5 & 22.7 & 147.4 \\
\hline & 22.5 & 22.8 & 146.7 \\
\hline & 23.5 & 22.9 & 146.0 \\
\hline & 22.5 & 23.0 & 145.3 \\
\hline & 22.5 & 23.0 & 145.3 \\
\hline \multirow{6}{*}{2300} & 22.5 & 23.1 & 144.7 \\
\hline & 23.0 & 23.2 & 144.1 \\
\hline & 23.5 & 23.3 & 143.5 \\
\hline & 23.5 & 23.4 & 142.8 \\
\hline & 23.5 & 23.4 & 142.8 \\
\hline & 23.0 & 23.5 & 142.3 \\
\hline \multirow[t]{7}{*}{2315} & 23.5 & 23.5 & 142.3 \\
\hline & 24.0 & 23.6 & 141.6 \\
\hline & 32.0 & 23.7 & $\{141.0$ \\
\hline & & 7 & 1 148.0 CMIV \\
\hline & 23.5 & 23.7 & 141.0 \\
\hline & 23.5 & 23.8 & 140.1 \\
\hline & 23.0 & 23.8 & 140.1 \\
\hline \multirow[t]{6}{*}{2330} & 23.0 & 23.9 & 139.8 \\
\hline & 24.5 & 24.0 & 139.3 \\
\hline & 23.5 & 24.0 & 139.3 \\
\hline & 23.5 & 24.1 & 138.7 \\
\hline & 23.5 & 24.1 & 138.7 \\
\hline & 23.5 & 24.1 & 138.7 \\
\hline
\end{tabular}


Fluorometer

\begin{tabular}{|c|c|c|c|}
\hline $\begin{array}{c}\text { Time } \\
\text { (hours) }\end{array}$ & $\begin{array}{c}\text { reading } \\
\text { (dial units) }\end{array}$ & $\begin{array}{c}\text { Average } \\
\text { (dial units) }\end{array}$ & $\begin{array}{c}\text { Discharge } \\
\text { (cfs) }\end{array}$ \\
\hline \multirow[t]{6}{*}{2345} & 24.0 & 24.2 & 138.1 \\
\hline & 23.5 & 24.2 & 138.1 \\
\hline & 23.5 & 24.3 & 137.5 \\
\hline & 24.5 & 24.3 & 137.5 \\
\hline & 24.5 & 24.3 & 137.5 \\
\hline & 24.5 & 24.4 & 137.0 \\
\hline \multirow[t]{6}{*}{2400} & 24.5 & 24.4 & 137.0 \\
\hline & 24.5 & 24.4 & 137.0 \\
\hline & 24.5 & 24.5 & 136.4 \\
\hline & 24.5 & 24.5 & 136.4 \\
\hline & 24.5 & 24.5 & 136.4 \\
\hline & 24.5 & 24.5 & 136.4 \\
\hline \multirow[t]{6}{*}{2415} & 23.5 & & \\
\hline & 22.0 & & \\
\hline & 21.0 & & \\
\hline & 20.0 & & \\
\hline & 15.0 & & \\
\hline & 12.5 & & \\
\hline \multirow[t]{6}{*}{2430} & 10.0 & & \\
\hline & 9.0 & & \\
\hline & 5.5 & & \\
\hline & 5.5 & & \\
\hline & 3.0 & & \\
\hline & 2.5 & & \\
\hline \multirow[t]{6}{*}{2445} & 2.5 & & \\
\hline & 1.5 & & \\
\hline & 0.5 & & \\
\hline & 0.0 & & \\
\hline & 0.0 & & \\
\hline & 0.0 & & \\
\hline 0100 & 0.0 & & \\
\hline
\end{tabular}




\section{APPENDIX C-PARIA RIVER TEST}

Fluorometer calibration: $29 \mathrm{ppb}=39.5$ on fluorometer dial.

Injection solution $=1,740,000 \mathrm{ppb}$.

Injection rate $=4.22 \mathrm{ml}$ per sec.

A smooth curve was passed through the plot of the fluorometer reading versus time. The value in the "Average" column was taken from this curve.

Discharge obtained by current-meter measurement is listed as CMM.

\begin{tabular}{|c|c|c|c|}
\hline $\begin{array}{c}\text { Time } \\
\text { (hours) }\end{array}$ & $\begin{array}{l}\text { Fluorometer } \\
\text { reading } \\
\text { (dial units) }\end{array}$ & $\begin{array}{c}\text { Average } \\
\text { (dial units) }\end{array}$ & $\begin{array}{c}\text { Discharge } \\
\text { (cfs) }\end{array}$ \\
\hline \multicolumn{4}{|c|}{ (Upper station) } \\
\hline 1100 & $\begin{array}{l}0.0 \\
0.0 \\
0.5 \\
1.0 \\
5.5 \\
7.5\end{array}$ & & \\
\hline 1115 & $\begin{array}{l}11.0 \\
17.5 \\
22.5 \\
31.0 \\
34.5 \\
39.0\end{array}$ & & \\
\hline
\end{tabular}


Fluorometer

\begin{tabular}{|c|c|c|c|}
\hline $\begin{array}{c}\text { Time } \\
\text { (hours) }\end{array}$ & $\begin{array}{c}\text { reading } \\
\text { (dial units) }\end{array}$ & $\begin{array}{c}\text { Average } \\
\text { (dial units) } \\
\end{array}$ & $\begin{array}{c}\text { Discharge } \\
\text { (cfs) }\end{array}$ \\
\hline \multirow[t]{6}{*}{1130} & 42.5 & & \\
\hline & 42.5 & & \\
\hline & 48.5 & & \\
\hline & 44.5 & & \\
\hline & 49.5 & & \\
\hline & 43.0 & & \\
\hline \multirow[t]{6}{*}{1145} & 43.5 & & \\
\hline & 43.5 & & \\
\hline & 43.0 & & \\
\hline & 42.5 & & \\
\hline & 43.5 & & \\
\hline & 41.5 & & \\
\hline \multirow[t]{6}{*}{1200} & 40.5 & & \\
\hline & 39.5 & 39.0 & 9.06 \\
\hline & 39.5 & 39.0 & 9.06 \\
\hline & 39.0 & 39.1 & 9.04 \\
\hline & 43.5 & 39.1 & 9.04 \\
\hline & 40.0 & 39.1 & 9.04 \\
\hline \multirow[t]{6}{*}{1215} & 39.5 & 39.2 & 9.02 \\
\hline & 40.0 & 39.2 & 9.02 \\
\hline & 39.0 & 39.2 & 9.02 \\
\hline & 38.5 & 39.3 & 9.00 \\
\hline & 43.0 & 39.3 & 9.00 \\
\hline & 39.5 & 39.3 & 9.00 \\
\hline \multirow[t]{6}{*}{1230} & 38.5 & 39.4 & 8. 97 \\
\hline & 38.5 & 39.4 & 8.97 \\
\hline & 39.5 & 39.4 & 8.97 \\
\hline & 39.5 & 39.5 & 8.94 \\
\hline & 40.0 & 39.5 & 8.94 \\
\hline & 39.5 & 39.5 & 8. 94 \\
\hline \multirow[t]{6}{*}{1245} & 40.0 & 39.6 & 8.92 \\
\hline & 39.5 & 39.6 & 8.92 \\
\hline & 39.5 & 39.6 & 8.92 \\
\hline & 39.5 & 39.7 & 8.90 \\
\hline & 39.5 & 39.7 & 8.90 \\
\hline & 39.5 & 39.7 & 8.90 \\
\hline
\end{tabular}


Fluorometer

\begin{tabular}{|c|c|c|c|}
\hline $\begin{array}{c}\text { Time } \\
\text { (hours) }\end{array}$ & $\begin{array}{c}\text { reading } \\
\text { (dial units) }\end{array}$ & $\begin{array}{c}\text { Average } \\
\text { (dial units) }\end{array}$ & $\begin{array}{c}\text { Discharge } \\
\text { (cfs) }\end{array}$ \\
\hline \multirow[t]{6}{*}{1300} & 40.0 & 39.8 & 8.88 \\
\hline & 39.5 & 39.8 & 8.88 \\
\hline & 39.5 & 39.8 & 8.88 \\
\hline & 40.5 & 39.9 & 8.85 \\
\hline & 44.5 & 39.9 & 8.85 \\
\hline & 39.5 & 39.9 & 8.85 \\
\hline \multirow[t]{6}{*}{1315} & 40.5 & 40.0 & 8.83 \\
\hline & 45.0 & 40.0 & 8.83 \\
\hline & 39.5 & 40.0 & 8.83 \\
\hline & 41.0 & 40.1 & 8.81 \\
\hline & 40.5 & 40.1 & 8.81 \\
\hline & 39.5 & 40.1 & 8.81 \\
\hline \multirow[t]{6}{*}{1330} & 39.5 & 40.2 & 8.79 \\
\hline & 39.0 & & \\
\hline & 38.0 & & \\
\hline & 28.5 & & \\
\hline & 28.5 & & \\
\hline & 24.5 & & \\
\hline \multirow[t]{6}{*}{1345} & 18.0 & & \\
\hline & 13.0 & & \\
\hline & 7.0 & & \\
\hline & 7.5 & & \\
\hline & 5.5 & & \\
\hline & 2.0 & & \\
\hline \multirow[t]{6}{*}{1400} & 3.0 & & \\
\hline & 2.0 & & \\
\hline & 1.0 & & $7.85 \mathrm{CMN}$ \\
\hline & 1.0 & & \\
\hline & 1.0 & & \\
\hline & 0.5 & & \\
\hline
\end{tabular}


Fluorometer

\begin{tabular}{|c|c|c|c|}
\hline $\begin{array}{c}\text { Time } \\
\text { (hours) }\end{array}$ & $\begin{array}{c}\text { reading } \\
\text { (dial units) }\end{array}$ & $\begin{array}{c}\text { Average } \\
\text { (dial units) }\end{array}$ & $\begin{array}{c}\text { Discharge } \\
\text { (cfs) }\end{array}$ \\
\hline \multicolumn{4}{|c|}{ (Lower station) } \\
\hline \multirow[t]{6}{*}{1200} & 0.0 & & \\
\hline & 0.5 & & \\
\hline & 0.0 & & \\
\hline & 0.0 & & \\
\hline & 0.0 & & \\
\hline & 0.5 & & \\
\hline \multirow[t]{6}{*}{1215} & 0.5 & & \\
\hline & 1.5 & & \\
\hline & 4.0 & & \\
\hline & 6.5 & & \\
\hline & 11.5 & & \\
\hline & 16.0 & & \\
\hline \multirow[t]{6}{*}{1230} & 20.5 & & \\
\hline & 24.0 & & \\
\hline & 28.5 & & \\
\hline & 34.5 & & \\
\hline & 37.5 & & \\
\hline & 41.0 & & \\
\hline \multirow[t]{6}{*}{1245} & 41.0 & & \\
\hline & 42.0 & & \\
\hline & 43.5 & & \\
\hline & 45.0 & & \\
\hline & 46.0 & & \\
\hline & 43.5 & & \\
\hline \multirow[t]{6}{*}{1300} & 46.5 & & \\
\hline & 45.5 & & \\
\hline & 44.5 & & \\
\hline & 45.5 & & \\
\hline & 45.5 & & \\
\hline & 42.5 & & \\
\hline
\end{tabular}




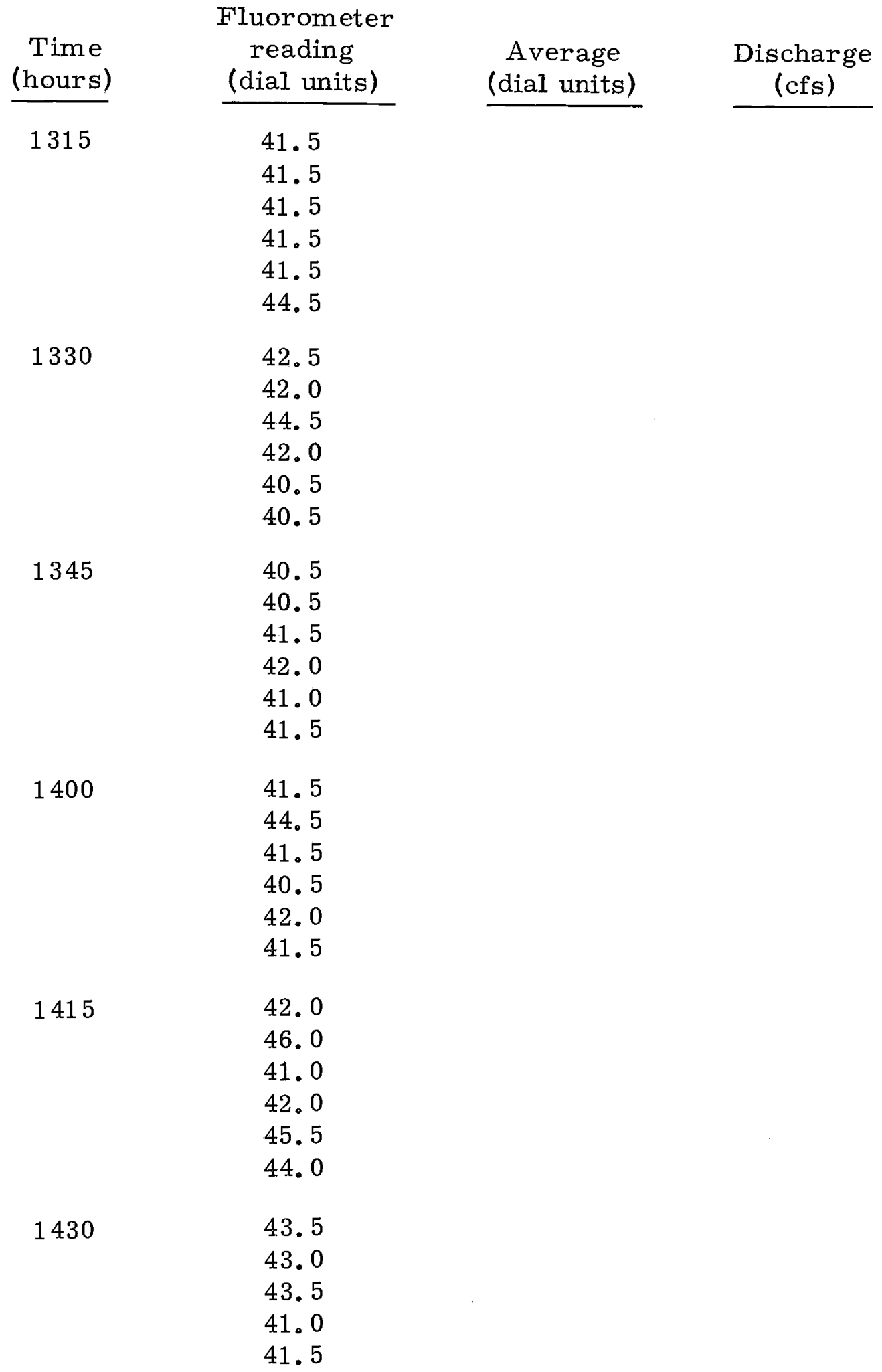




\section{APPENDIX D-CHINLE WASH TEST}

Fluorometer calibration: $108 \mathrm{ppb}=49.5$ on fluorometer dial.

Injection solution $=1,700,000 \mathrm{ppb}$.

Injection rate $=4.22 \mathrm{ml}$ per sec.

A smooth curve was passed through the plot of the fluorometer reading versus time. The value in the "Average" column was taken from this curve.

\begin{tabular}{|c|c|c|c|}
\hline $\begin{array}{c}\text { Time } \\
\text { (hours) }\end{array}$ & $\begin{array}{l}\text { Fluorometer } \\
\text { reading } \\
\text { (dial units) }\end{array}$ & $\begin{array}{c}\text { Average } \\
\text { (dial units) }\end{array}$ & $\begin{array}{c}\text { Discharge } \\
\text { (cfs) }\end{array}$ \\
\hline \multirow[t]{6}{*}{1215} & 0.0 & & \\
\hline & 0.0 & & \\
\hline & 0.0 & & \\
\hline & 0.0 & & \\
\hline & 0.0 & & \\
\hline & 1.0 & & \\
\hline \multirow[t]{6}{*}{1230} & 1.5 & & \\
\hline & 2.0 & & \\
\hline & 3.0 & & \\
\hline & 4.0 & & \\
\hline & 5.0 & & \\
\hline & 6.5 & & \\
\hline \multirow[t]{6}{*}{1245} & 8.0 & & \\
\hline & 9.5 & & \\
\hline & 11.5 & & \\
\hline & 13.0 & & \\
\hline & 15.0 & & \\
\hline & 17.0 & & \\
\hline
\end{tabular}


Fluorometer

\begin{tabular}{|c|c|c|c|}
\hline $\begin{array}{c}\text { Time } \\
\text { (hours) }\end{array}$ & $\begin{array}{c}\text { reading } \\
\text { (dial units) } \\
\end{array}$ & $\begin{array}{c}\text { Average } \\
\text { (dial units) }\end{array}$ & $\begin{array}{c}\text { Discharge } \\
\text { (cfs) }\end{array}$ \\
\hline \multirow[t]{6}{*}{1300} & 18.0 & & \\
\hline & 20.5 & & \\
\hline & 21.0 & & \\
\hline & 21.5 & & \\
\hline & 23.0 & & \\
\hline & 24.5 & & \\
\hline \multirow{6}{*}{1315} & 25.5 & & \\
\hline & 25.5 & & \\
\hline & 26.5 & & \\
\hline & 27.5 & & \\
\hline & 27.5 & & \\
\hline & 28.5 & & \\
\hline \multirow[t]{6}{*}{1330} & 28.5 & 29.0 & 4.00 \\
\hline & 29.0 & 29.3 & 3.96 \\
\hline & 29.5 & 29.5 & 3.94 \\
\hline & 29.5 & 29.8 & 3.90 \\
\hline & 29.5 & 30.0 & 3.87 \\
\hline & 30.0 & 30.2 & 3.85 \\
\hline \multirow[t]{6}{*}{1345} & 30.5 & 30.4 & 3.82 \\
\hline & 30.0 & 30.5 & 3.80 \\
\hline & 30.0 & 30.6 & 3.79 \\
\hline & 30.0 & 30.7 & 3.78 \\
\hline & 30.5 & 30.9 & 3.76 \\
\hline & 30.0 & 31.0 & 3.75 \\
\hline \multirow[t]{6}{*}{1400} & 30.5 & 31.1 & 3.73 \\
\hline & 31.0 & 31.2 & 3.72 \\
\hline & 31.0 & 31.3 & 3.71 \\
\hline & 30.5 & 31.4 & 3.70 \\
\hline & 30.5 & 31.4 & 3.70 \\
\hline & 30.5 & 31.5 & 3.68 \\
\hline \multirow[t]{6}{*}{1415} & 31.0 & 31.5 & 3.68 \\
\hline & 30.5 & 31.5 & 3.68 \\
\hline & 30.0 & 31.5 & 3.68 \\
\hline & 30.5 & 31.5 & 3.68 \\
\hline & 31.0 & 31.6 & 3.67 \\
\hline & 31.5 & 32.0 & 3.63 \\
\hline
\end{tabular}




\begin{tabular}{|c|c|c|c|}
\hline $\begin{array}{l}\text { Time } \\
\text { (hours) }\end{array}$ & $\begin{array}{c}\text { Fluorometer } \\
\text { reading } \\
\text { (dial units) } \\
\end{array}$ & $\begin{array}{c}\text { Average } \\
\text { (dial units) }\end{array}$ & $\begin{array}{c}\text { Discharge } \\
\text { (cfs) }\end{array}$ \\
\hline \multirow[t]{6}{*}{1430} & 32.5 & 33.0 & 3.52 \\
\hline & 33.5 & 34.0 & 3.42 \\
\hline & 34.0 & 34.5 & 3.37 \\
\hline & 34.5 & 35.5 & 3.28 \\
\hline & 35.5 & 36.5 & 3.19 \\
\hline & 37.5 & 37.2 & 3.13 \\
\hline \multirow[t]{6}{*}{1445} & 38.5 & 38.0 & 3.07 \\
\hline & 39.0 & 39.0 & 3.00 \\
\hline & 40.5 & 40.0 & 2.92 \\
\hline & 40.5 & 40.6 & 2.87 \\
\hline & 41.5 & 41.5 & 2.81 \\
\hline & 42.5 & 42.5 & 2.74 \\
\hline \multirow[t]{6}{*}{1500} & 43.0 & 43.2 & 2.69 \\
\hline & 45.0 & 44.0 & 2.64 \\
\hline & 44.5 & 45.0 & 2.58 \\
\hline & 46.0 & 45.7 & 2.54 \\
\hline & 47.0 & 46.5 & 2.50 \\
\hline & 46.5 & 47.5 & 2.45 \\
\hline \multirow[t]{6}{*}{1515} & 48.0 & 48.3 & 2.40 \\
\hline & 48.0 & & \\
\hline & 49.5 & & \\
\hline & 49.5 & & \\
\hline & 50.0 & & \\
\hline & 50.5 & & \\
\hline 1530 & 50.5 & & \\
\hline
\end{tabular}




\section{REF ERENCES}

Andre, H., 1964, Hydrometrie pratique des cours d'eau: Division Technique Generale de la Production Hydraulique d'Electricite de France.

Barsby, A., and Cole, J. A., 1963, The calibration of two flumes by salt dilution: Water and Water Eng., June, p. 1-4.

Carter, R.W., and Anderson, I. E., 1963, Accuracy of current meter measurements: Am. Soc. Civil Engineers Proc., Jour. Hydraulics Div., v. 89, no. HY4, p. 105-115.

Corbett, D. M., and others, 1943, Stream-gaging procedure-a manual describing methods and practices of the Geological Survey: U.S. Geol. Survey Water-Supply Paper 888, 245 p.

Feuerstein, D. L。, and Selleck, R。 E。, 1963, Fluorescent tracers for dispersion measurements: Am. Soc. Civil Engineers Proc., Jour. Sanitary Engineering Div., v. 89, no. SA4, pt. 1, p. 1-21.

G. K. Turner Associates, 1964, Operating and service manual-model III fluorometer: Palo Alto, Calif., G. K. Turner Associates, $6 \mathrm{p}$.

Grover, N. C., and Harrington, A. W., 1943, Stream flow measurements, records and their uses: New York, John Wiley and Sons, Inc., $354 \mathrm{p}$.

Linsley, R. K., Jr., Kohler, M. A., and Paulhus, J. L. H., 1958, Hydrology for engineers: New York, McGraw-Hill Book Co., Inc., $340 \mathrm{p}$. 
U.S. Bureau of Reclamation, Lynch Radiation Services, and University of California, 1961, Report on field demonstration use of isotopes in hydrographic measurements, Gila Project, Arizona: U.S. Bur. Reclamation, duplicated report, 73 p.

U.S. Inter-Agency Committee on Water Resources, 1965, A study of methods used in measurement and analysis of sediment loads in streams: Minneapolis, Minn., St. Anthony Falls Hydraulic Lab., Report J, 5 p.

Wright, R. R., and Collings, M. R., 1964, Application of fluorescent tracing techniques to hydrologic studies: Am. Water Works Assoc. Jour., v. 56, no. 6, p. 748-754. 